\title{
Reactive oxygen species-responsive miR-210 regulates proliferation and migration of adipose-derived stem cells via PTPN2
}

\author{
$\mathrm{JH} \mathrm{Kim}^{1,2,5}$, SG Park ${ }^{3,5}$, S-Y Song ${ }^{4}, \mathrm{JK} \mathrm{Kim}^{3}$ and J-H Sung ${ }^{\star, 1,2,3}$
}

Hypoxia enhances the proliferation and migration of adipose-derived stem cells (ASCs) via the generation of reactive oxygen species (ROS). Therefore, this study primarily investigated whether or not ROS generation could regulate microRNA-210 (miR210) expression, and increase proliferation/migration of ASCs. In addition, we tried to identify the signaling pathways involved in miR-210 upregulation and the direct target genes of miR-210 that mediate these functions. Various sources of ROS generation such as hypoxia, antimycin, rotenone, and platelet-derived growth factor (PDGF)-BB upregulated miR-210 expression, and increased the proliferation/migration of ASCs. There is a positive feed-forward loop between ROS generation and miR-210, and miR-210 itself increases ROS generation by downregulation of iron-sulfur cluster scaffold homolog 2 (ISCU2). Although hypoxiainducible factor-1 $\alpha$ was not involved in miR-210 expression, pharmacological or small interfering RNA (siRNA)-driven inhibition of Akt and ERK1/2 molecules reduced miR-210 expression. Transfection of siRNAs of NF- $\kappa$ B and Elk1 also reduced miR-210 expression, indicating that these signaling pathways mediate miR-210 upregulation. Protein tyrosine phosphatase, non-receptor type 2 (PTPN2) was selected for miR-210 target gene, and it was downregulated by ROS generators or miR-210 mimic treatment. PTPN2 was first proven to be a direct miR-210 target in luciferase activity assay, and pharmacological inhibition or overexpression of PTPN2 regulated the proliferation and migration of ASC. In conclusion, ROS generation from diverse sources induces miR-210 expression in ASCs via PDGFR- $\beta$, Akt and ERK pathways. Transcription of miR-210 expression is regulated by NF- $\kappa$ B and Elk1, and miR-210 increases the proliferation and migration of ASCs via ISCU2 and PTPN2 downregulation.

Cell Death and Disease (2013) 4, e588; doi:10.1038/cddis.2013.117; published online 11 April 2013

Subject Category: Experimental Medicine

Adipose-derived stem cells (ASCs) are isolated from subcutaneous fat and used for tissue repair and regeneration. Culturing ASCs in hypoxia ( $2 \%$ oxygen) increases their proliferation, migration and secretion of growth factors. ${ }^{1-3}$ In addition, hypoxia preconditioning enhances regenerative potential of ASCs in vivo. ${ }^{4-6}$ In a previous study, we investigated the key mediators and signal pathways involved in the stimulation of ASCs during hypoxia and found that reactive oxygen species (ROS) play a key role. Furthermore, exposure to a low concentration of antimycin or rotenone significantly increased the proliferation and migration of ASCs. $^{7}$ Hypoxia and ROS generation induced the phosphorylation of platelet-derived growth factor receptor- $\beta$ (PDGFR- $\beta$ ), ERK1/2 and Akt. ${ }^{8}$ Like this, acute responses of ASCs to hypoxia and ROS generation were investigated in our previous studies, but intermediate or chronic responses to hypoxia (i.e. microRNA regulation) have not been demonstrated.
Hypoxia influences cellular functions, including metabolism, survival, proliferation, migration and angiogenesis. All of these cellular functions are directly and indirectly controlled by a master transcription factor called hypoxia-inducible factor- $1 \alpha$ $(\mathrm{HIF}-1 \alpha){ }^{9,10}$ In response to hypoxia, HIF-1 $\alpha$ levels increase a specific set of microRNA molecules called miR-210. This unique microRNA is highly expressed in hypoxic cells and tissues, and is reportedly regulated by HIF- $1 \alpha$ stabilization. ${ }^{11-13}$ Therefore, miR-210 is currently considered the 'master microRNA' of the hypoxic response, ${ }^{14}$ and is known to influence physiological development as well as a number of hypoxia-dependent disease states. miR-210 mediates these functions by regulating a lot of target mRNAs. ${ }^{15}$ For example, ephrin A3 and protein tyrosine phosphatase 1B (PTP1B) were validated as direct targets of $\mathrm{miR}-210$, and downregulation of these proteins improves heart disease. ${ }^{16}$ Similarly, iron-sulfur cluster scaffold homolog1/2 (ISCU1/2) facilitates the assembly of iron-sulfur clusters and regulates mitochondrial

\footnotetext{
${ }^{1}$ Department of Applied Bioscience, CHA University, Seoul, Korea; ${ }^{2}$ Stem Cell Research Laboratory, CHA Stem Cell Institute, Seoul, Korea; ${ }^{3}$ Department of Biomedical Science, CHA University, Seoul, Korea and ${ }^{4}$ Department of Plastic and Reconstructive Surgery, CHA Bundang Medical Center, CHA University, Seongnam-si, Kyunggido, Korea

*Corresponding author: J-H Sung, Department of Applied Bioscience, CHA University, No. 606-16, Yeoksam-dong, Kangnam-gu, Seoul 135-081, Korea. Tel: 8223468 3598; Fax: 8223468 3373; E-mail: brian99@empal.com

${ }^{5}$ These authors contributed equally to this work.

Keywords: adipose-derived stem cell; miR-210; reactive oxygen species; Elk1; NF-кB; PTPN2

Abbreviations: ASC, adipose-derived stem cell; ROS, reactive oxygen species; PDGF, platelet-derived growth factor; PDGFR- $\beta$, platelet-derived growth factor receptor- $\beta$; HIF-1 $\alpha$, hypoxia-inducible factor-1 $\alpha$; miR-210, microRNA-210; PTP1B, protein tyrosine phosphatase 1B; ISCU, iron-sulfur cluster scaffold homolog; NAC, N-acetyl-cysteine; DCF-DA, 2',7'-dichlorofluorescein diacetate; Nox4, NADPH oxidase 4; PTPN2, protein tyrosine phosphatase, non-receptor type 2; siRNA, small interfering RNA; Q-PCR, quantitative real-time PCR; ChIP, chromatin immunoprecipitation

Received 23.1.13; revised 28.2.13; accepted 7.3.13; Edited by E Candi
} 
metabolism. ${ }^{17}$ Furthermore, another direct target of miR-210, known as 'max-binding protein', controls the cell cycle and proliferation through reciprocal upregulation of c-myc activity. ${ }^{18}$

Despite the knowledge that hypoxia enhances the proliferation and migration of ASCs via ROS generation, there has been no direct evidence that $\mathrm{miR}-210$ is regulated by intracellular ROS generation and it mediates proliferation/ migration of ASCs. In addition, there are some evidences that expression of miR-210 is independent of HIF- $1 \alpha$ pathway, but it was regulated by Akt- or TNF- $\alpha$-related pathways. ${ }^{19,20}$ Therefore, this study investigated: (1) Whether or not ROS generation regulates miR-210 expression, and increase proliferation/migration of ASCs? (2) Which signaling pathway(s) and transcription factor(s) are involved in the upregulation of miR-210? (3) What is (are) miR-210 target gene(s) involved in proliferation and migration of ASCs? We first found that ROS generation induces miR-210 expression, and identified the novel transcription factors and target genes of miR-210 in this study.

\section{Results}

Increased miR-210 expression by ROS generators. In a preliminary study, microRNA array was carried out to screen the altered microRNAs during hypoxia. The signal of hsamiR-29a, -301a, -503 and -539 was slightly decreased (approximately 0.5 -fold), but the signal of miR-210 was highly increased during hypoxia ( $>100$-fold).

In the first place, we confirmed the miR-210 expression using quantitative real-time PCR (Q-PCR), and found that hypoxia (2\%) significantly increased the miR-210 expression in a time-dependent manner (Figure 1a; $P<0.01$ ). miR-210 expression was not altered until $6 \mathrm{~h}$ under hypoxia. After $6 \mathrm{~h}$, miR-210 expression started to increase, and it was highest at $24 \mathrm{~h}$. Hypoxia-induced expression of miR-210 was attenuated by the ROS scavenger, such as $N$-acetyl-cysteine (NAC), indicating that hypoxia-increased miR-210 expression is mainly mediated by ROS generation (Figure $1 \mathrm{~b} ; P<0.01$ ). Because NADPH oxidase 4 (Nox4) is involved in ROS generation by hypoxia, we investigated whether or not Nox4 knockdown attenuates miR-210 expression. However, Nox4 small interfering RNA (siRNA) partially reduced the hypoxiainduced miR-210 expression (Figure 1c; $P<0.01$ ), indicating that there are alterative ROS-generating systems in ASCs.

Therefore, we tested whether or not mitochondrial ROS generators could also induce miR-210 expression, and found that antimycin $(10 \mathrm{nM})$ and rotenone $(10 \mathrm{pM})$ significantly increased the miR-210 expression in a time-dependent manner (Figure 1d; $P<0.01$ ). miR-210 expression was increased after $6 \mathrm{~h}$, and was highest at $24 \mathrm{~h}$. Therefore, miR-210 expression was usually measured at $24 \mathrm{~h}$ after the treatment throughout the experiments.

Dose-dependent regulation of miR-210 by ROS generation was investigated. The results showed that low concentrations of antimycin (at 10 and $100 \mathrm{nM}$; Figure 1e; $P<0.01$ ) and rotenone (at 10 and $100 \mathrm{pM}$; Figure 1f; $P<0.01$ ) significantly increased the miR-210 expression, while high concentrations display no significant expression. This is consistent with our previous study that high concentrations of ROS generator did not increase the proliferation and migration of ASCs. ${ }^{7}$
Increased ROS generation by miR-210 mimic treatment. We also investigated whether or not miR-210 upregulation could induce ROS generation in ASCs. ${ }^{21,22}$ ROS generation was measured by flow cytometry (Figure 2a), and the florescence intensity of $2^{\prime}, 7^{\prime}$-dichlorofluorescein diacetate (DCF-DA) was significantly increased by the transfection of miR-210 mimic (Figure 2b; $P<0.01$ ). In addition, fluorescence microscope images show that fluorescence signal of DCF-DA (green) was increased after transfection of miR-210 mimic compared with the negative/scramble control that did not contain miR-210 mimic (Figure 2c). These results indicate the positive feed-forward loop between ROS generation and miR-210 upregulation (ROS/miR210/ROS pathway) in ASCs (Supplementary Scheme 1).

ISCU2 involvement in ROS generation. It has been reported that $\mathrm{PTP} 1 \mathrm{~B}$ and ISCU1/2 are direct target of miR-210, and inhibition of these genes increases ROS generation. ${ }^{16,21,22}$ Therefore, we further investigated whether or not these genes regulate ROS generation. However, downregulation of PTP1B by siRNA technique induced neither ROS generation nor proliferation/migration of ASCs (data not shown).

Although mRNA expression of ISCU1/2 was not reduced, transfection of miR-210 mimic (20 and $50 \mathrm{nM})$ primarily reduced the protein level of ISCU2 in western blot analysis (Figure 2d). Therefore, we investigated whether or not ISCU1/ 2 downregulation could affect ROS generation. Transfection of SiRNA $(5 \mathrm{nM})$ for ISCU1/2 reduced the ISCU1/2 protein level, but ISCU2 is primarily reduced by siRNA (Figure 2e). In addition, transfection of SiRNA for ISCU1/2 increased the signal intensity of DCF-DA according to flow cytometry (Figure 2f), indicating that increased ROS generation might be due to downregulation of ISCU2 (Figure 2g; $P<0.01$ ). In addition, transfection of siRNA for ISCU1/2 partially induced the proliferation (Supplementary Figure 1a) and migration (Supplementary Figure 1b) of ASCs.

Regulation of ASC proliferation by miR-210. In addition to $2 \%$ hypoxia, low dose of antimycin $(10 \mathrm{nM})$ and rotenone $(10 \mathrm{pM})$ significantly increased the proliferation of ASCs in CCK assay (Figure 3a; $P<0.01$ ). Because the proliferation of ASCs and the miR-210 expression are simultaneously increased by ROS generation, we tested whether or not miR-210 expression is involved in the proliferation of ASCs.

Hypoxia-induced proliferation of ASCs was attenuated by the transfection of miR-210 inhibitor (10 and $20 \mathrm{nM}$; Figure 3b; $P<0.01$ ). In addition, antimycin- (Figure 3c; $P<0.01$ ) and rotenone-induced (Figure $3 d ; P<0.01$ ) proliferation were significantly reduced by transfection of miR-210 inhibitor. On the contrary, transfection of miR-210 mimic (10 and $20 \mathrm{nM}$ ) significantly increased the proliferation of ASCs (Figures 3e; $P<0.01)$. Collectively, these results indicate that upregulation of miR-210 is involved in the proliferation of ASCs.

Increased stemness gene expression by miR-210. Stemness genes such as Oct4 and Rex1 have been reported to regulate proliferation of $A S C s .{ }^{23,24}$ Thus, we measured the stemness gene expression after miR-210 mimic treatment. Although mRNA expression of Nanog, Sox2, Klf4 and c-Myc 

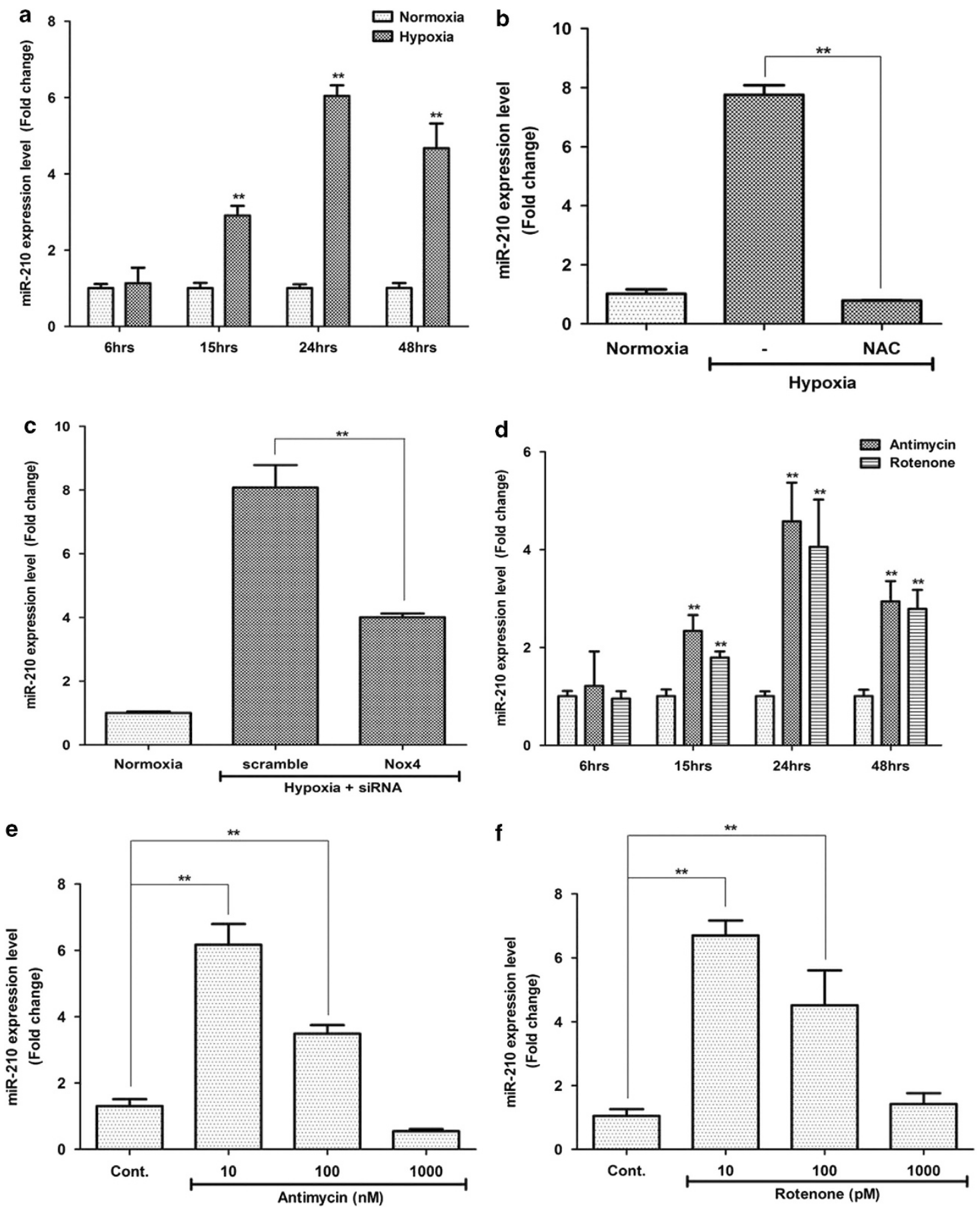

Figure 1 ROS generation induces miR-210 expression. Q-PCR was carried out to measure miR-210 expression after various ROS generator treatment. (a) Hypoxia (2\%) increased the miR-210 expression in a time-dependent manner. (b) Hypoxia significantly increased the miR-210 expression, but it was attenuated by ROS inhibitor, NAC $(0.1 \mathrm{mM})$. (c) Transfection of Nox4 siRNA partially reduced the hypoxia-induced miR-210 expression. (d) Mitochondrial ROS generators such as antimycin (10 nM) and rotenone (10 pM) induced the miR-210 expression in a time-dependent manner. (e and f) Concentration-dependent miR-210 expression. The expression of miR-210 was induced by low concentrations of antimycin ( 10 or $100 \mathrm{nM}, \mathrm{e})$ and rotenone (10 or $100 \mathrm{pM}, \mathrm{f})$, rather than the high concentration. ${ }^{*} P<0.01$

did not change in reverse transcription-polymerase chain reaction (RT-PCR) (data not shown), that of Oct4 and Sox2 was induced by transfection of miR-210 mimic $(20 \mathrm{nM})$ (Figure $3 \mathrm{f}$ ). We also confirmed the increased expression of Oct4 and Rex1 in Q-PCR (Figure 3g).
Regulation of ASC migration by miR-210. Similar to the ASC proliferation, ROS generation induces the migration of ASCs in cell scratch assay (Figure $4 a ; P<0.01$ ). Hypoxiainduced migration of ASCs was attenuated by the transfection of miR-210 inhibitor (20 and $50 \mathrm{nM}$; Figure 4b; 
a
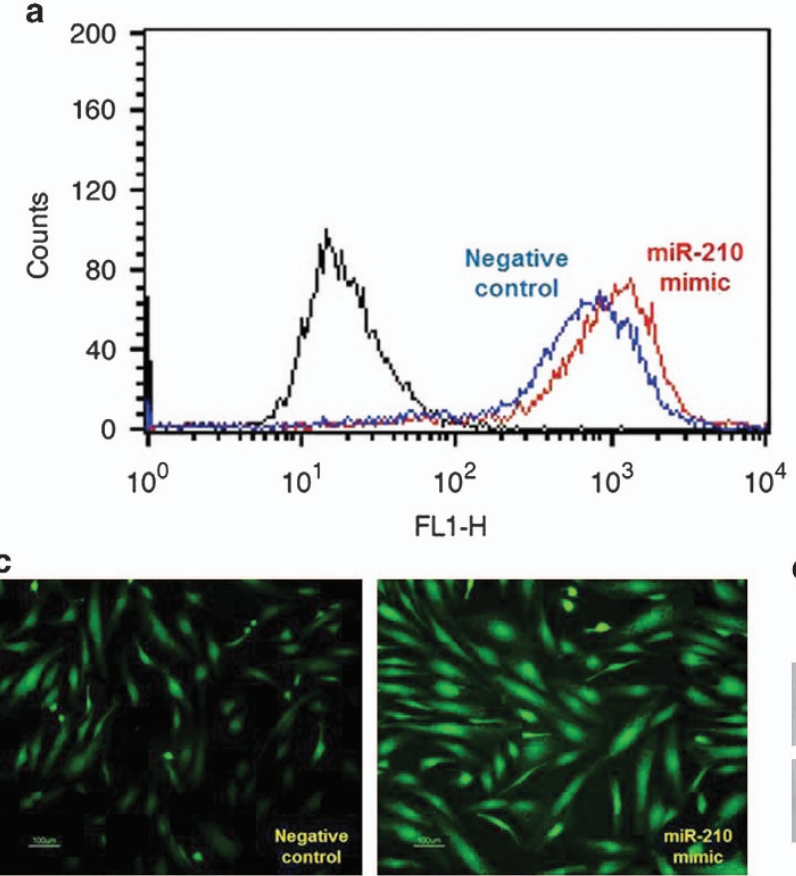

FL1-H

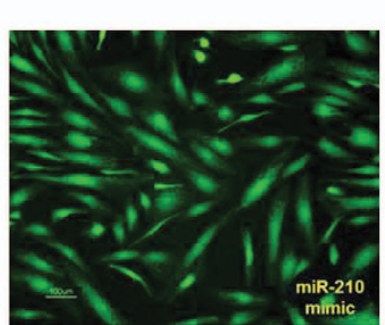

b

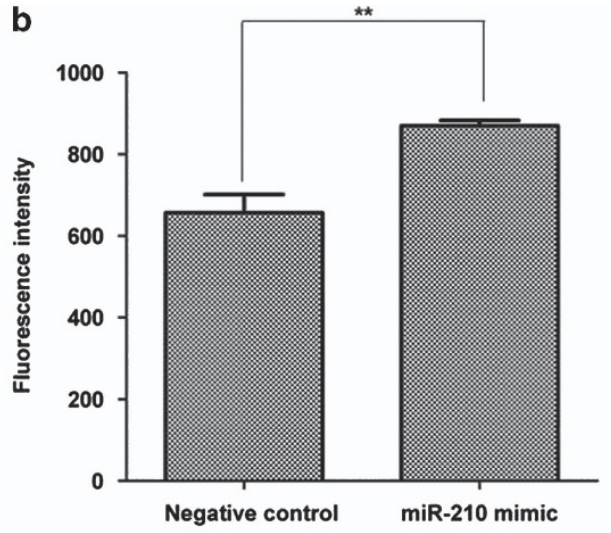

\section{d}

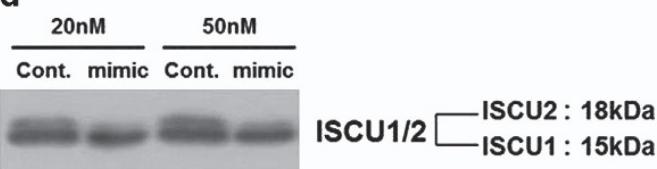

$\beta$-actin

e

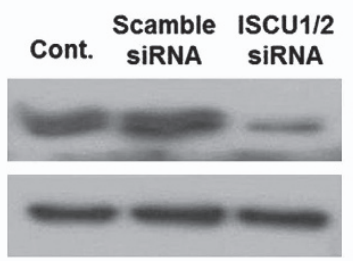

ISCU1/2 $\square$ ISCU2: $18 \mathrm{kDa}$
ISCU1 : $15 \mathrm{kDa}$

$\beta$-actin
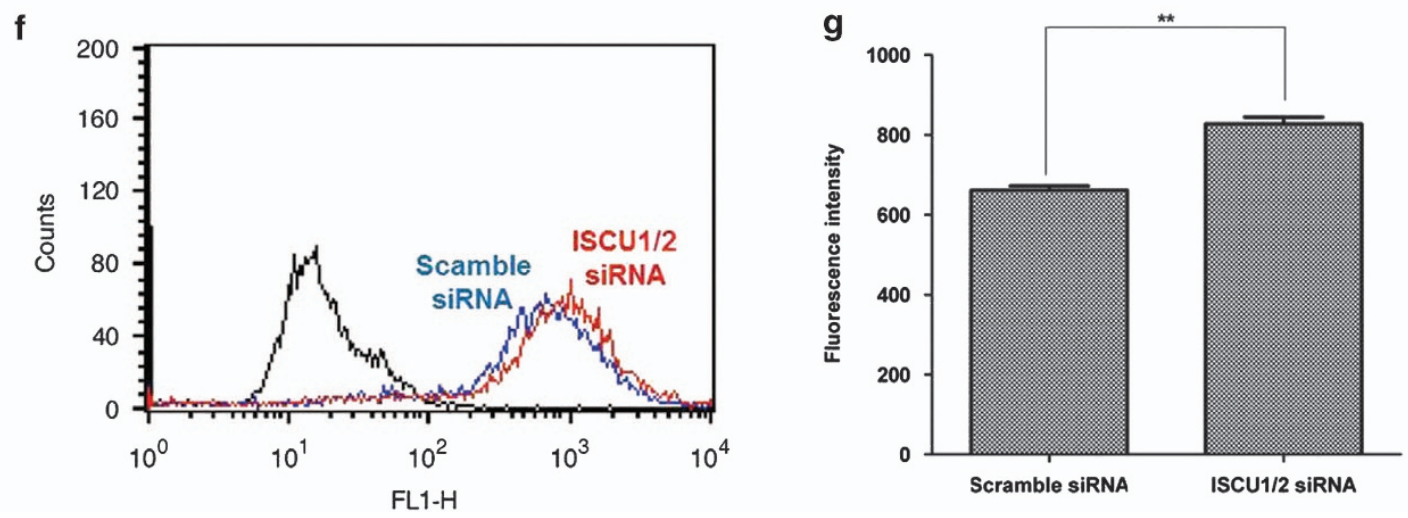

Figure 2 Positive feed-forward loop between miR-210 expression and ROS generation. Transfection of miR-210 mimic increased ROS generation by ISCU1/2 downregulation. ( $(\mathbf{a}$ and $\mathbf{b})$ Transfection of miR-210 mimic increased the fluorescence intensity of DCF-DA in flow cytometry (a), and then the geometric mean was measured (b). (c) Fluorescence microscopic image of DCF-DA signal after miR-210 mimic transfection ( $20 \mathrm{nM})$. (d) Transfection of miR-210 mimic primarily reduced the ISCU2 expression in western blot analysis. (e) Transfection of siRNA ( $5 \mathrm{nM})$ for ISCU1/2 reduced the ISCU1/2 protein level, but ISCU2 is primarily reduced by siRNA. (f and $\mathbf{g}$ ) Transfection of siRNA for ISCU1/2 increased the signal intensity of DCF-DA in flow cytometry $(\mathbf{f})$, and then the geometric mean of fluorescence intensity was measured (g). ${ }^{* \star} P<0.01$

$P<0.01$ ). In addition, antimycin- (Figure 4c; $P<0.01$ ) and rotenone-induced migrations (Figure $4 \mathrm{~d} ; P<0.01$ ) of ASCs were significantly reduced by transfection of miR-210 inhibitor. On the contrary, transfection of miR-210 mimic $(10,20$ and $50 \mathrm{nM})$ significantly increased the migration of ASCs (Figure 4e; $P<0.01$ ). Collectively, these results indicate that upregulation of $\mathrm{miR}-210$ expression is involved in the migration of ASCs.
HIF-1 $\alpha$-independent miR-210 regulation. It is well known that miR-210 is primarily regulated by HIF-1 $\alpha$ stabilization; ${ }^{12,13,25}$ therefore, we investigated whether or not ROS-induced miR-210 expression is regulated by HIF-1 $\alpha$ pathway. Although hypoxia $(2 \%)$ increased the protein level of HIF- $1 \alpha$, a low dose of antimycin $(10 \mathrm{nM})$ and rotenone (10 pM) treatment did not induce HIF-1 $\alpha$ level in western blot analysis (Figure 5a). In addition, hypoxia-induced HIF-1 $\alpha$ 

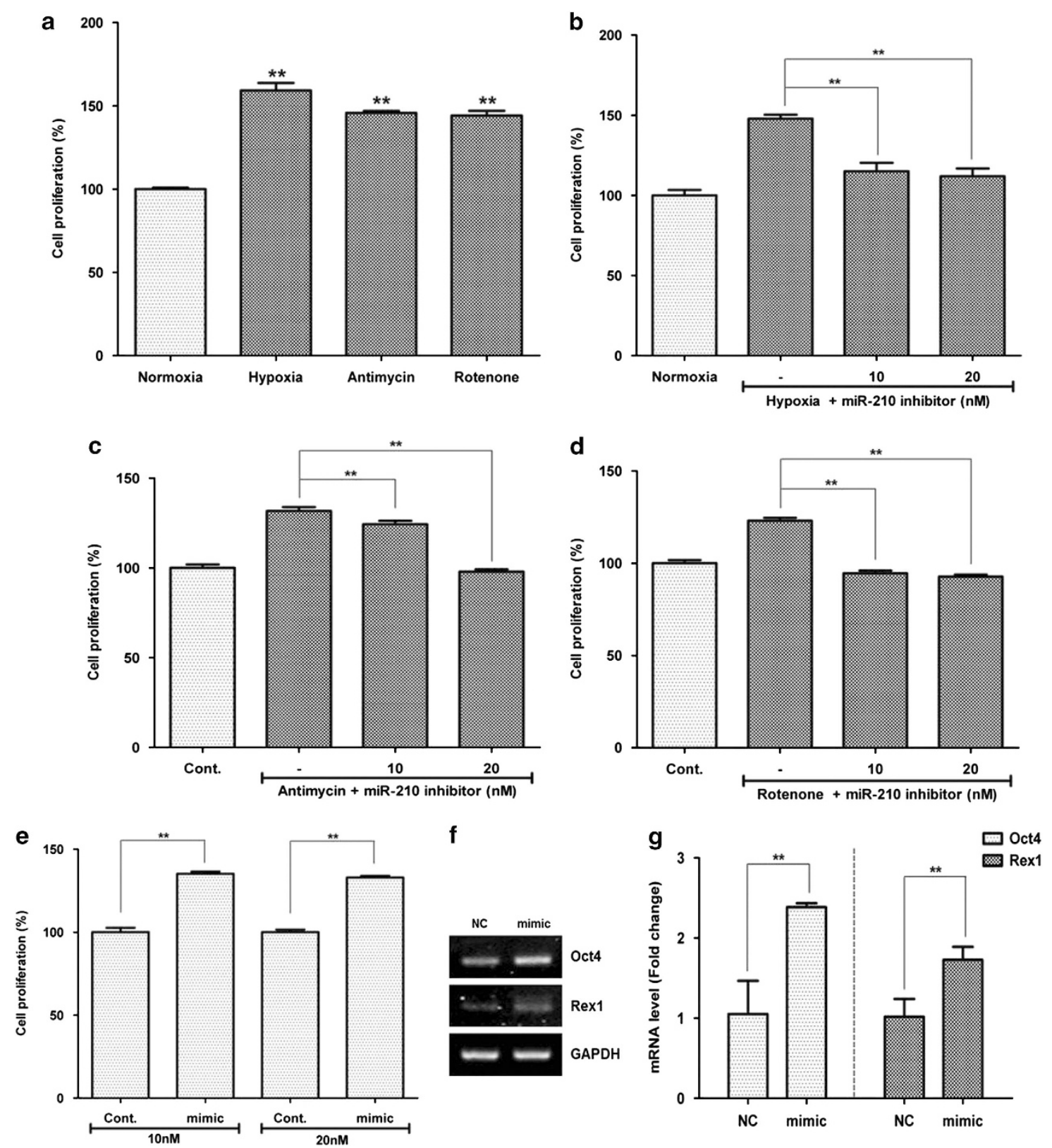

Figure 3 Increased proliferation and stemness gene expression by miR-210. ASC proliferation was measured using Cell Counting Kit (CCK) assay at $48 \mathrm{~h}$ and $\mathrm{mRNA}$ expression of stemness genes were measured at $24 \mathrm{~h}$ after transfection of miR-210 mimic. (a) Hypoxia ( $2 \%$ ) and low concentrations of antimycin (10 nM) and rotenone (10 pM) significantly increased the proliferation of ASCs. (b-d) Hypoxia- (b), antimycin- (c) and rotenone- (d)induced proliferations were attenuated by transfection of miR-210 inhibitor. (e) On the contrary, transfection of miR-210 mimic significantly increased the proliferation of ASCs. (f) mRNA expression of Oct4 and Rex1 was measured at $24 \mathrm{~h}$ after transfection of miR-210 mimic. (g) Q-PCR for Oct4 and Rex1. ${ }^{\star \star} P<0.01$. Con, control; GAPDH, glyceraldehyde 3-phosphate dehydrogenase; NC, negative control

expression was not attenuated by ROS scavenger, NAC (Figure 5b). Of note, Yc-1 (3-(5'-hydroxymethyl-2'-furyl)-1benzyl indazole) (i.e. HIF-1 $\alpha$ inhibitor) treatment did not reduce the miR-210 expression (Figure 5c). Collectively, these results indicate that ROS-induced miR-210 expression is independent of HIF-1 $\alpha$ in ASCs.

On the other hand, we tested whether or not paracrine effects of ASCs could be regulated by miR-210. Although hypoxia-induced mRNA expression of vascular endothelial growth factor (VEGF) and hepatocyte growth factor were inhibited by $\mathrm{Yc}_{\mathrm{c}} 1$ treatment, it was not altered by the transfection of miR-210 mimic (Supplementary Figure 2). These results suggest that secretion of paracrine factors are not regulated by miR-210, but mainly by HIF- $1 \alpha$ level under hypoxia (Supplementary Scheme 1).

Signal pathways involved in miR-210 upregulation. Because ASC stimulation by hypoxia was accompanied by the phosphorylation of signaling molecules such as PDGFR- $\beta$, ERK $1 / 2$ and $\mathrm{Akt}^{8}{ }^{8}$ we further investigated whether or not these signaling pathways are involved in miR-210 upregulation. 

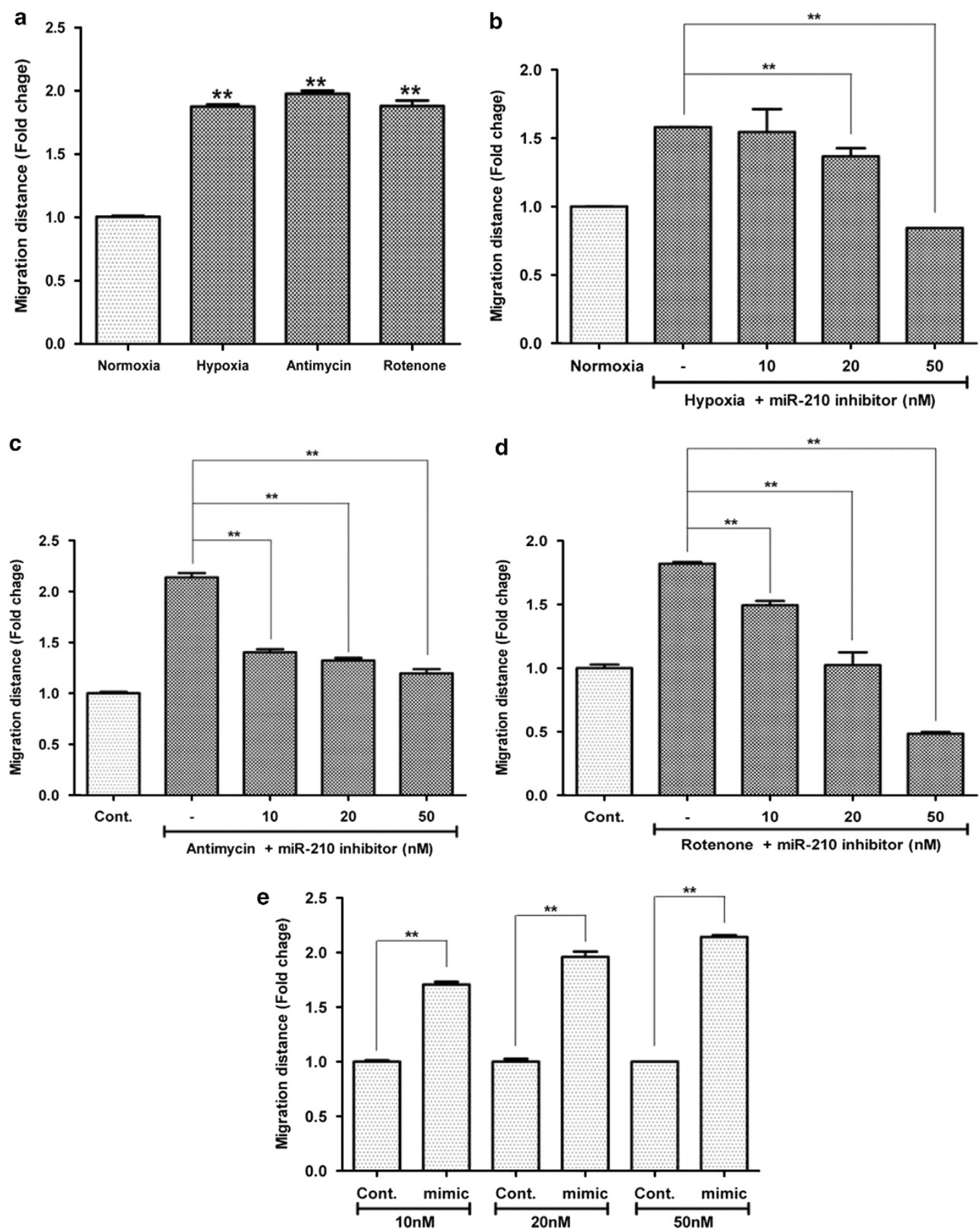

Figure 4 Increased migration by miR-210. ASC migration was measured using scratch migration assay at $24 \mathrm{~h}$ after the cell wounding. (a) Hypoxia (2\%) and low concentrations of antimycin $(10 \mathrm{nM})$ and rotenone $(10 \mathrm{pM})$ significantly increased the migration of ASCs. (b-d) Hypoxia- (b), antimycin- (c) and rotenone- (d) induced migrations were attenuated by transfection of miR-210 inhibitor. (e) On the contrary, transfection of miR-210 mimic significantly increased the migration of ASCs. ${ }^{* *} P<0.01$. Con, control

In western blot analysis (Figure 5d), phosphorylation of PDGFR- $\beta$, ERK1/2 and Akt molecules was increased by antimycin $(10 \mathrm{nM})$ and rotenone $(10 \mathrm{pM})$ treatments. On the contrary, pharmacological inhibitors of PDGFR- $\beta$, ERK1/2 and Akt pathway downregulated the miR-210 expression. Antimycin-induced miR-210 expression (Figure 5e; $P<0.01$ ) was significantly attenuated by AG1296 (a PDGFR inhibitor, $10 \mu \mathrm{M}$ ), LY-294002 (a PI3K/Akt inhibitor, $5 \mu \mathrm{M}$ ) and U0126 (an MAPK/ERK inhibitor, $5 \mu \mathrm{M}$ ). Likewise, rotenone-induced miR-210 expression (Figure 5f; $P<0.01$ ) was significantly decreased by AG1296, LY-294002 and U0126. These results indicate that the phosphorylation of PDGFR- $\beta$, followed by the 
phosphorylation of Akt, ERK1/2 might be involved in miR-210 upregulation (Supplementary Scheme 1).

NF- $\kappa$ B and Elk1 induce miR-210 transcription. Using Patch 1.0 and AliBaba 2.1 program, we searched for the possible transcription factors that promote the expression of miR-210 during ROS generation. The promoter region of miR-210 was analyzed to get some candidates. Because Akt and ERK pathways are involved in miR-210 expression and there are $\mathrm{NF}-\kappa \mathrm{B}$ and Elk1 binding sequence in the upstream region of the promoter sequence, we selected NF- $\mathrm{B}$ and Elk1 as strong candidates for miR-210 transcription factors (Figure 5g).

As expected, phosphorylation of $\mathrm{NF}-\kappa \mathrm{B}$ and Elk1 was significantly increased by low concentration of antimycin (10 nM; Figure 5h) and rotenone (10 pM; Figure 5i) treatments in western blot analysis. On the contrary, siRNA transfection of NF- $\kappa \mathrm{B}$ and Elk1 (20 nM each) significantly decreased the antimycin-induced miR-210 expression in ASCs (Figure 5j; $P<0.01)$. Similarly, siRNA transfection of NF- $\kappa B$ and Elk1 reduced the rotenone-induced miR-210 expression in ASCs (Figure $5 \mathrm{k} ; P<0.01$ ). These results suggest that ROS induce the transcription of miR-210 primarily via NF- $\kappa \mathrm{B}$ and Elk1 phosphorylation.

Chromatin immunoprecipitation (ChIP) assay was performed to identify the binding site of phosphorylated NF- $\kappa \mathrm{B}$ and Elk1 in the upstream region of miR-210 promoter. As shown in Figure 5l, antimycin and rotenone treatment significantly increased the signal intensity of PCR products, which indicated that phosphorylated NF- $\kappa \mathrm{B}$ and Elk1might bind to -113 to -123 and -582 to -595 regions, respectively, of the miR-210 promoter (Figure $5 \mathrm{~g}$ ).

PDGF-BB induces miR-210 through ROS generation. Although PDGFR- $\alpha$ is highly expressed, ${ }^{26}$ treatment of PDGF-AA is not as effective as PDGF-BB in the proliferation and migration of ASCs (our unpublished data). In addition, PDGF-AA $(<10 \mathrm{ng} / \mathrm{ml})$ treatment did not induce miR-210 expression and ROS generation (Supplementary Figures $3 a$ and b). On the contrary, PDGF-BB treatment (5 or $10 \mathrm{ng} / \mathrm{ml}$ ) induced ROS generation (Figure 6a) and significantly increased the miR-210 expression in a time-dependent manner (Figure 6b; $P<0.01$ ). In addition, PDGF-BB increased the proliferation (Figure 6c; $P<0.01$ ) and migration (Figure $6 \mathrm{~d} ; P<0.01$ ) of ASCs in a concentration-dependent manner. Of interest, transfection of specific siRNA (20 nM) for PDGFR- $\beta$ significantly downregulated miR-210 expression (Figure 6e; $P<0.01$ ), which indicates that PDGF-BB/ PDGFR- $\beta$ signaling pathway plays a key role in miR-210 upregulation. Furthermore, PDGF-BB-induced miR-210 expression level was significantly reduced by transfection of specific siRNAs for Akt $(20 \mathrm{nM})$ and ERK1/2 (20 nM) (Figure 6f; $P<0.01$ ).

PTPN2 is down-regulated under hypoxia. A microarray analysis was used to clarify the target genes of miR-210 (Supplementary Figure 4a). Hypoxia-incubated $\left(2 \% \mathrm{O}_{2}\right)$ cells significantly upregulated 329 genes ( $>2$-fold, $P<0.05$ ), but downregulated 15 genes of ASCs ( $<2$-fold, $P<0.05$ ) (Supplementary Figure 4B). Analysis of gene ontology using the differentially expressed genes demonstrated that the genes related to signal transduction $(20 \%)$, transcription (17\%), cell proliferation (10\%) and cell differentiation $(9 \%)$ were primarily upregulated by hypoxia (Supplementary Figure 4C).

PTPN2 is a direct miR-210 target. Using 'microinspector' software (available at: http://bioinfo.uni-plovdiv.bg/microinspector/), we selected protein tyrosine phosphatase, nonreceptor type 2 (PTPN2) as miR-210 target from 15 genes downregulated by hypoxia (Supplementary Figure 4D). As expected, mRNA and protein expression of PTPN2 was downregulated at $24 \mathrm{~h}$ after hypoxia (Figure $7 \mathrm{a}$ ). In addition, Ct value for PTPN2 was measured by Q-PCR, and PTPN2 mRNA was significantly decreased under hypoxia (Figure $7 \mathrm{~b}$; $P<0.01)$. It is well known that microRNA negatively regulates protein expression by interacting with the $3^{\prime}$ untranslated regions of specific mRNA. However, 12 nucleotide sequences in miR-210 are complementary to the coding sequence of PTPN2, which might induce degradation of PTPN2 mRNA (Figure 7c). Similar to hypoxia, antimycin $(10 \mathrm{nM})$ and rotenone $(10 \mathrm{pM})$ treatment decreased the mRNA expression of PTPN2 (Figure 7d). Transfection of miR-210 mimic $(20 \mathrm{nM})$ downregulated the PTPN2 mRNA and protein levels (Figure 7e). Using luciferase activity assay, we investigated whether or not PTPN2 is a direct target of miR-210 (Figure 7f). miR-210 mimic significantly reduced the PTPN2 luciferase activity in HEK293 cells (Figure 7g; $P<0.01$ ). Although miR-210 reduced wild-type PTPN2 in HEK293 cells $(P<0.01)$, it did not reduce the luciferase activity of mutant PTPN2 (Figure 7h). Collectively, these results suggest that PTPN2 is a direct target of miR-210.

To confirm whether or not PTPN2 mediates proliferation and migration of ASCs, pharmacological inhibitors for PTPN2 (ethyl-3,4-dephostatin) and transfection of PTPN2 cDNA clone were used. As expected, ethyl-3,4-dephostatin increased the proliferation (Figure 7i; $P<0.01$ ) and migration (Figure 7j; $P<0.01$ ) of ASCs. PTPN2 reported to regulate the phosphorylation of PDGFR- $\beta,{ }^{27,28}$ and ethyl-3,4dephostatin treatment also induced the phosphorylation of PDGFR- $\beta$ in ASCs (Supplementary Figure 5). On the contrary, overexpression of PTPN2 decreased the hypoxiainduced proliferation (Figure 7k) and migration (Figure 7l) of ASCs. These results suggest that miR-210 downregulates PTPN2 to exhibit the increased proliferation and migration of ASCs.

\section{Discussion}

MicroRNAs exert their actions primarily at the post-transcriptional level, either via translational repression and/or mRNA degradation. ${ }^{29,30}$ This study attempted to identify a novel microRNA involved in the proliferation and migration of ASCs during hypoxia and ROS generation. In a microRNA array analysis and Q-PCR, miR-210 expression was significantly increased by various ROS generators (i.e. hypoxia, antimycin, rotenone and PDGF-BB). Transfection of miR-210 inhibitor significantly attenuated the ROS-mediated proliferation and migration of ASCs, while that of miR-210 mimic induced the 


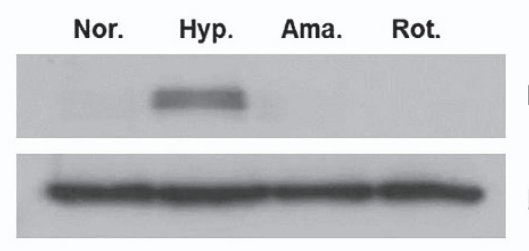

c

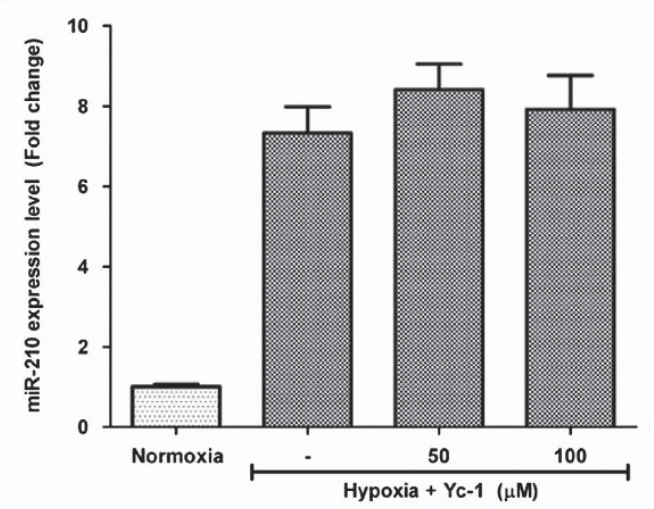

e

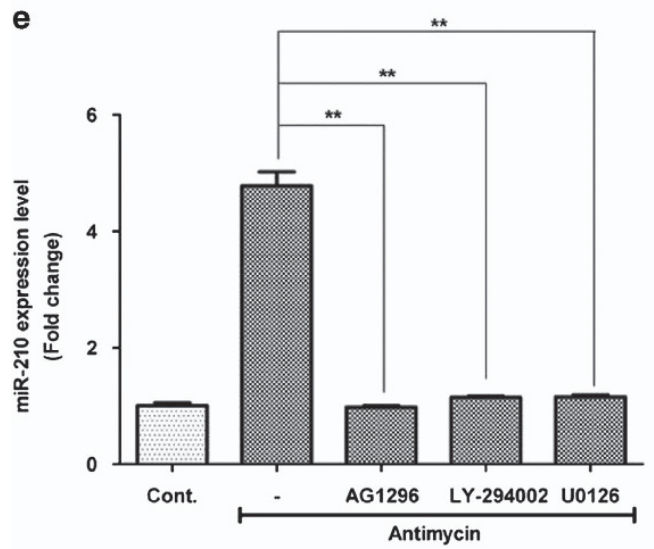

g

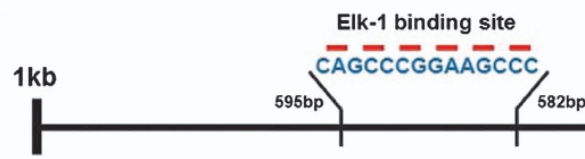

h

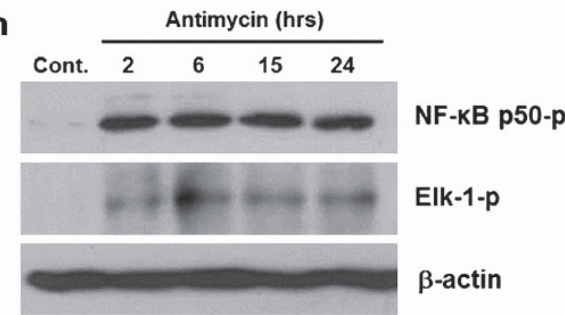

b

HIF-1 $\alpha$

$\beta$-actin

d
HIF-1 $\alpha$

$\beta$-actin

Cont. Ama. Rot

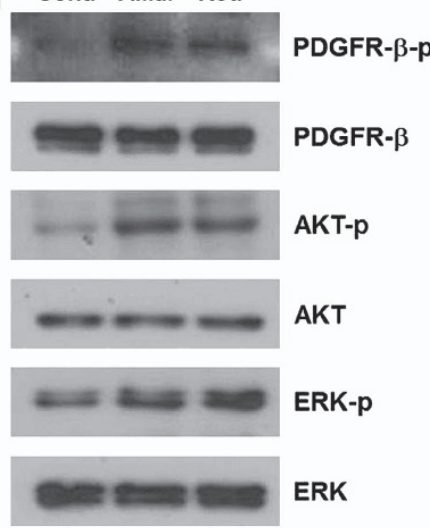

PDGFR- $\beta-p$ f

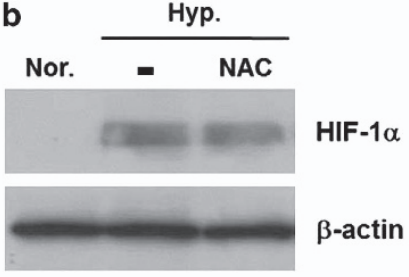

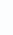
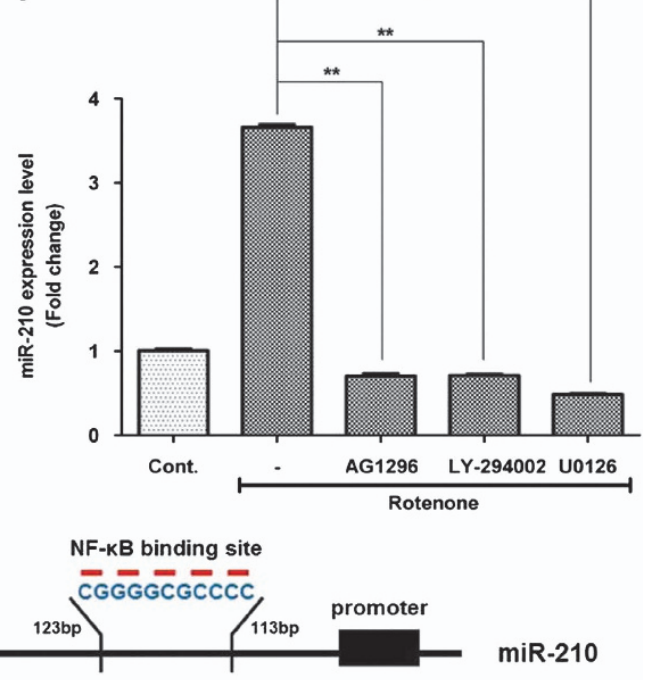

i

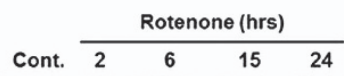

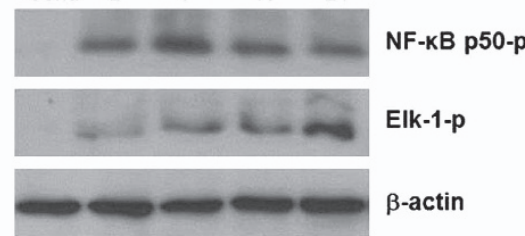

Figure 5 Signal pathway and transcription factor involved in miR-210 upregulation. ROS generators induce miR-210 level not only by HIF- $1 \alpha$ stabilization but also by phosphorylation of PDGFR- $\beta$, Akt and ERK1/2. In addition, NF- $\kappa$ B and Elk1 are involved in the transcription of miR-210. (a) Although hypoxia (Hyp.) (2\%) induced HIF-1 $\alpha$ level, low concentrations of antimycin (Ama.) and rotenone (Rot.) did not in western blot analysis. (b) HIF-1 $\alpha$ was not reduced by ROS scavenger, NAC. (c) Hypoxia-induced miR-210 expression was not reduced by an HIF-1 $\alpha$ inhibitor (Yc-1, 50 and $100 \mu \mathrm{M}$ ). (d) Phosphorylation of PDGFR- $\beta$, Akt and ERK 1/2 molecules was significantly increased by antimycin $(10 \mathrm{nM})$ and rotenone $(10 \mathrm{pM})$ treatment according to western blot analysis. (e, f) Antimycin- (e) and rotenone- (f) induced miR-210 expressions were significantly reduced by AG1296 (a PDGFR inhibitor, $10 \mu \mathrm{M}$ ), LY-294002 (a PI3K/Akt inhibitor, $5 \mu \mathrm{M}$ ) and U0126 (an MAPK/ERK inhibitor, $5 \mu \mathrm{M}$ ). (g) The promoter region upstream of miR210 was analyzed using Patch 1.0 and AliBaba 2.1 program, and NF- $k$ B and Elk1 were found to be candidates for miR-210 transcription factors. (h, i) Phosphorylation of NF- $k B$ and Elk1 was induced by antimycin $(10 \mathrm{nM}, \mathrm{h})$ and rotenone (10 pM, i) treatment. (j, k) In addition, antimycin- (j) and rotenone- (k) induced miR-210 expression was significantly attenuated by transfection of siRNA for NF- $k B(20 \mathrm{nM})$ and Elk1 $(20 \mathrm{nM})$. (I) ChIP assay shows that antimycin and rotenone treatment significantly increased the signal intensity of PCR products, which indicated that phosphorylated NF- $\kappa \mathrm{B}$ and Elk1 could bind to the upstream region of miR-210 promoter. ${ }^{* *} P<0.01$. Con, control; Norm., normaxia 

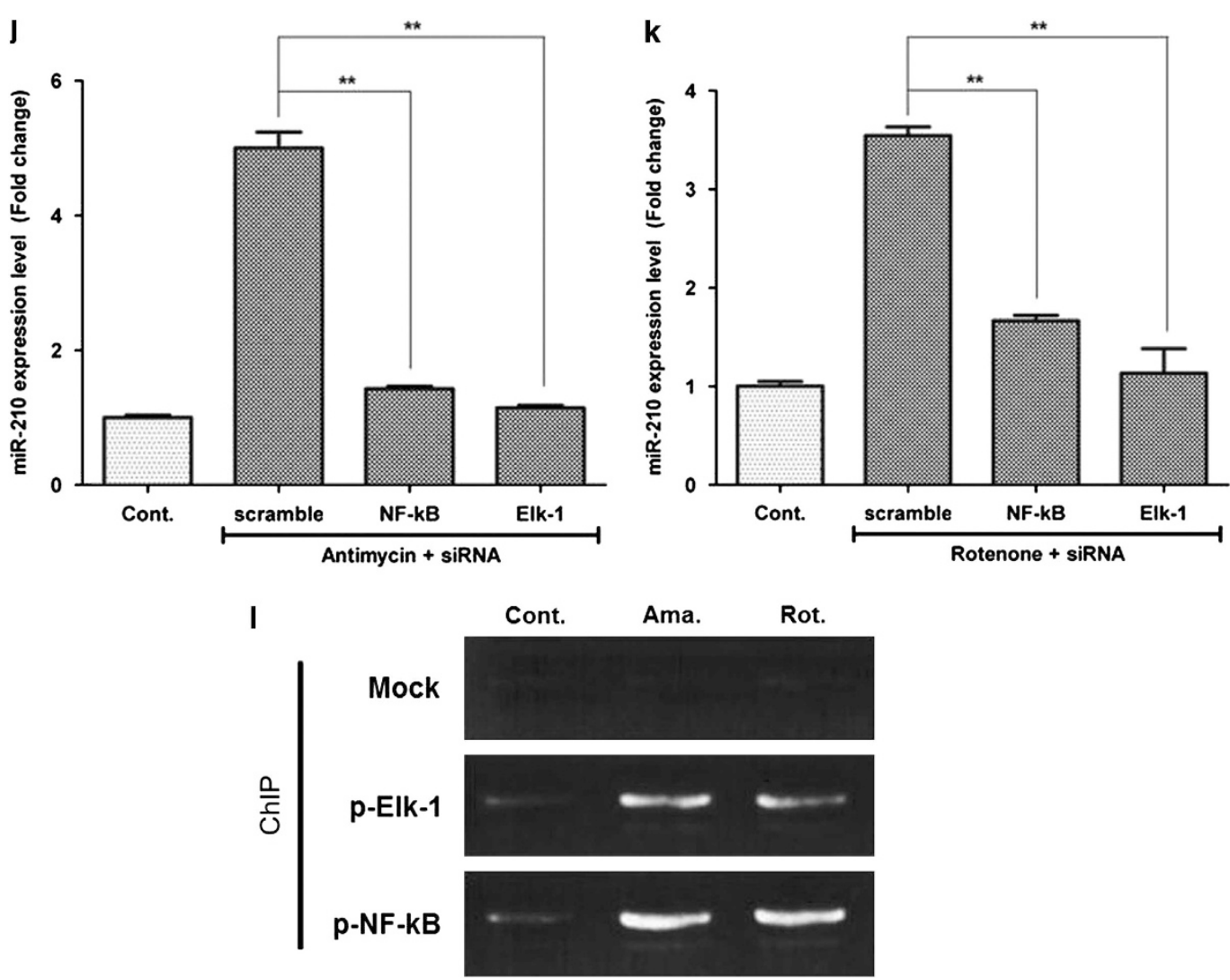

Figure 5 (Continued)

proliferation and migration of ASCs. These results suggest that miR-210 is a key player in ROS-associated events in ASCs (Supplementary Scheme 1). miR-210 has been known as 'hypoxamiR' because it appears to control a network of multiple processes during the hypoxic responses. ${ }^{31}$ However, since our study first identified 'ROS' as a regulatory mechanism of miR-210 expression, miR-210 could be renamed as 'ROSmiR'.

It has been reported that ROS generation or miR-210 expression is involved in adipocyte differentiation. ${ }^{32-35} \mathrm{How}$ ever, it is controversial whether ROS generation induces or reduces adiopocyte differentiation of ASCs. For example, antimycin (1-10 mM) and rotenone treatment induced adipocyte differentiation in ASCs in our preliminary study, but Nox4 silencing unexpectedly induced adipogenesis. This is consistent with the previous report that Nox4 knockout induced adipocyte differentiation in vivo. ${ }^{36}$ Although Qin et al. ${ }^{35}$ suggested that miR-210 could promote adipocyte differentiation by repressing WNT signaling through targeting Tcf7l2 in 3T3L1 cells, miR-210 was not highly induced during adipocyte differentiation of ASCs and treatment of miR-210 mimic did not induce the adipocyte differentiation in our preliminary study. Therefore, it is not clear whether or not ROS generation and miR-210 induce or reduce adipocyte differentiation in this stage, and further studies should be extended to define the role of ROS and miR-210 in ASC differentiation.

Many reports have shown evidence of the involvement of HIF- $1 \alpha$ pathway in $\mathrm{miR}-210$ upregulation and of a feedback response between miR-210 and HIF-1 $\alpha .{ }^{11,13,37,38}$ For example, transfection of HIF-1 $\alpha$ in HT-29 cells significantly increased miR-210 expression. ${ }^{38}$ Similarly, green tea polyphenol, EGCG, suppressed lung cancer cell viability by upregulating both HIF- $1 \alpha$ and miR-210. ${ }^{11}$ Kelly et al. ${ }^{37}$ also demonstrated that hypoxia promotes $\mathrm{HIF}-1 \alpha$ stability through suppression of the expression of glycerol-3-phosphate dehydrogenase 1-like protein by miR-210. However, this study demonstrated HIF- $1 \alpha$-independent miR-210 induction by ROS generation. For example, low concentration of antimycin and rotenone did not induce HIF-1 $\alpha$ levels (Figure 5a), and Yc-1 (an HIF-1 $\alpha$ inhibitor) did not reduce miR-210 expression under hypoxia (Figure $5 \mathrm{c}$ ). Therefore, it is reasonable that miR-210 upregulation by low concentrations of ROS generators is independent of HIF-1 $\alpha$ pathway.

Until now, little is known about HIF-independent miR-210 regulation. Mutharasan et al. ${ }^{39}$ first reported that miR-210 was upregulated in hypoxic cardiomyocytes through Akt- and p53-dependent pathways, and exerted cytoprotective effects through both HIF-dependent and -independent regulation. ${ }^{39}$ This study focused on the HIF-independent miR-210 regulation by ROS generation. Specifically, phosphorylation of PDGFR- $\beta$ is followed by phosphorylation of Akt and ERK1/2, which induces the phosphorylation of miR-210 transcription factors such as NF- $\kappa \mathrm{B}$ and Elk1. In addition to Akt and NF- $\kappa \mathrm{B}$, we first found the novel signal molecules and transcription factors that PDGFR- $\beta$, ERK1/2 and Elk1 are involved in miR-210 induction. 
a

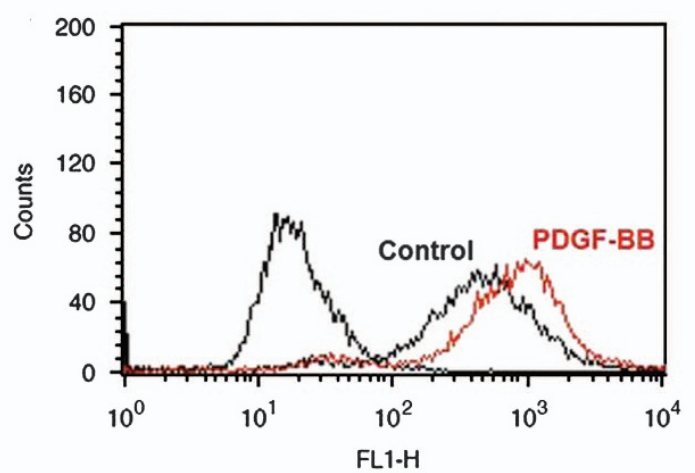

C
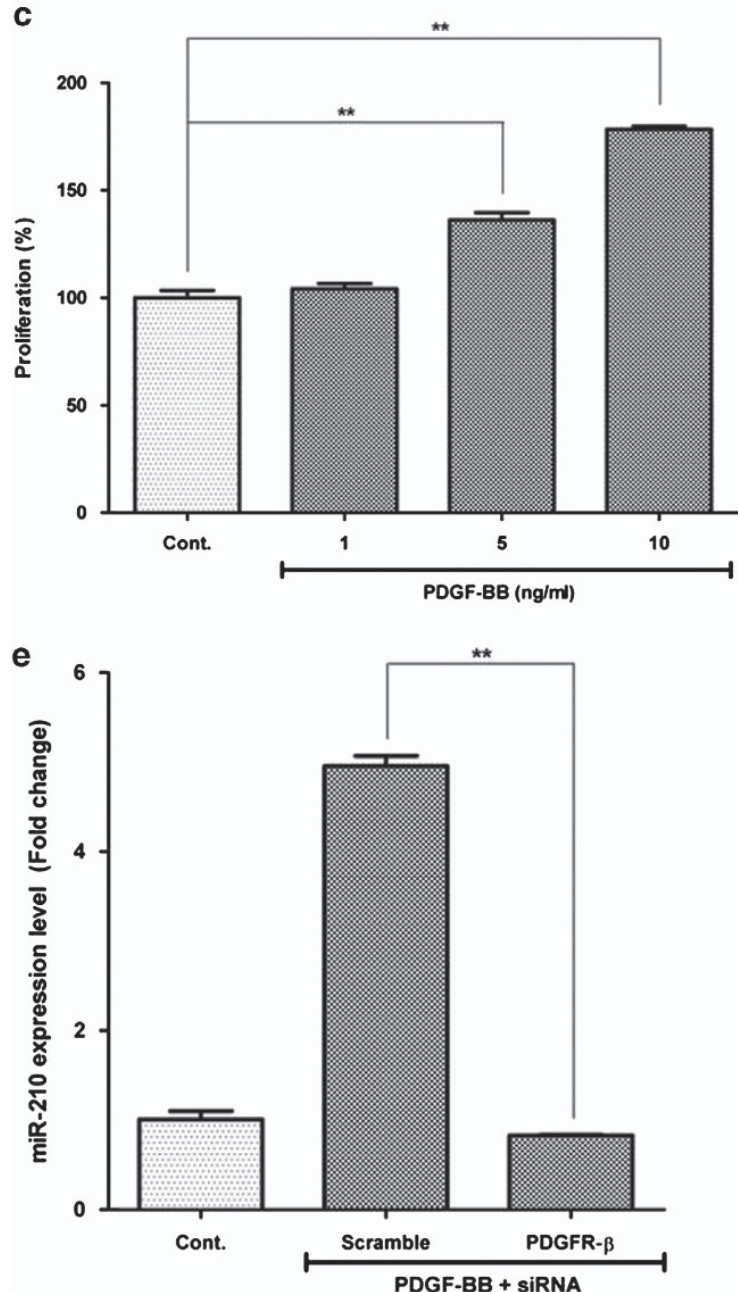

b

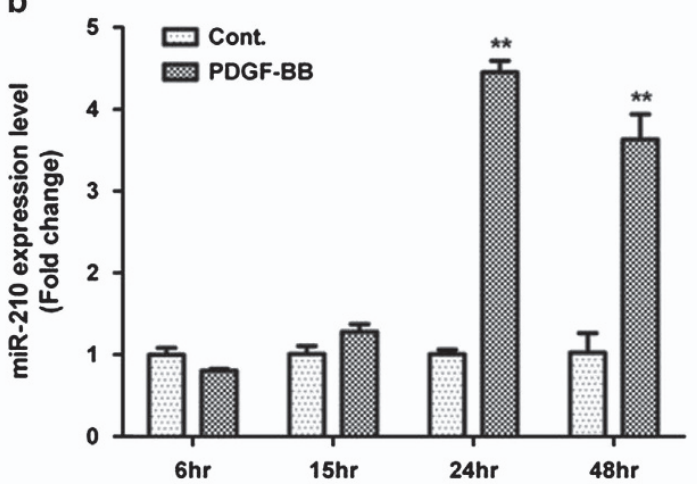

d

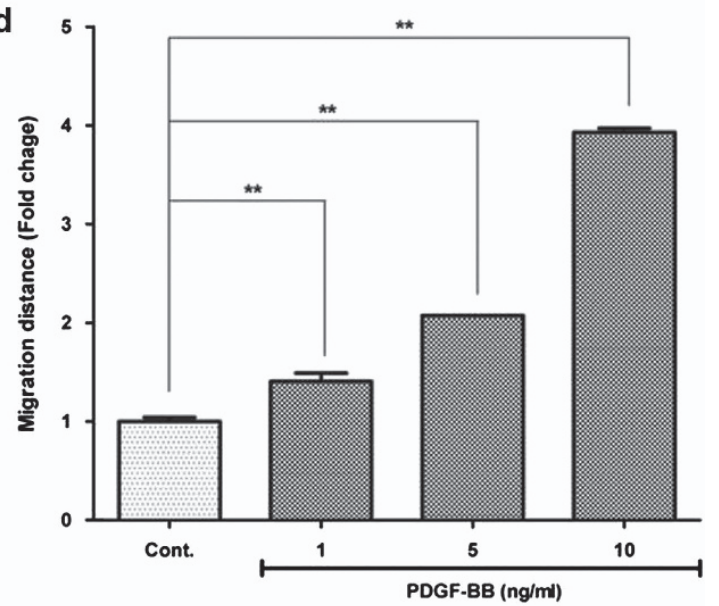

f

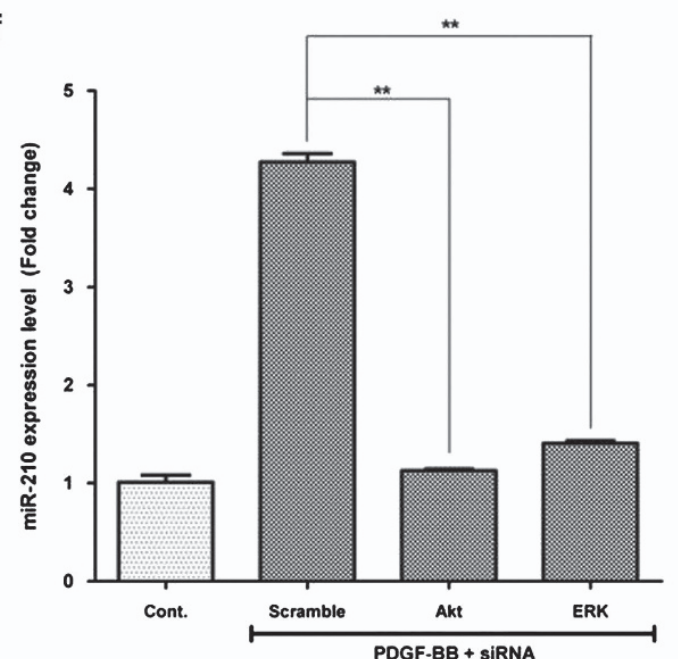

Figure 6 miR-210 upregulation by PDGF-BB/PDGFR- $\beta$ pathway. PDGF-BB treatment induces ROS generation and increased the miR-210 expression via Akt and Erk1/2 pathways. (a) PDGF-BB (10 ng/ml) treatment induces ROS generation in flow cytometry. (b) miR-210 expression was measured by Q-PCR, and significantly increased by PDGF-BB $(10 \mathrm{ng} / \mathrm{ml})$ treatment. (c) Proliferation of ASCs was measured by CCK assay, and it was induced by PDGF-BB treatment. (d) Migration of ASCs was measured by scratch migration assay, and it was induced by PDGF-BB treatment. (e) Transfection of specific siRNA for PDGFR- $\beta(20 \mathrm{nM})$ attenuated the PDGF-BB-induced miR-210 expression in ASCs. (f) Transfection of specific siRNA for Akt (20 nM) and ERK1/2 (20 nM) also reduced the PDGF-BB (10 ng/ml)-induced miR-210 expression. ${ }^{* *} P<0.01$. Con, control

Protein tyrosine phosphatases are natural receptor tyrosine kinase antagonists and serve as regulators of both non-receptor and receptor tyrosine kinases..$^{40,41}$ Of them, PTPN2 is a ubiquitously expressed phosphatase and is implicated in the regulation of growth factor receptor signaling.
PTPN2 directly controlled the PDGFR- $\beta$ phosphorylation in a site-selective manner, and also negatively regulated the migratory response to PDGF-BB. ${ }^{27}$ In addition, loss of PTPN2 specifically redirected the PDGFR- $\beta$ toward rapid recycling and induced PDGFR- $\beta$-related signal pathways, 
a
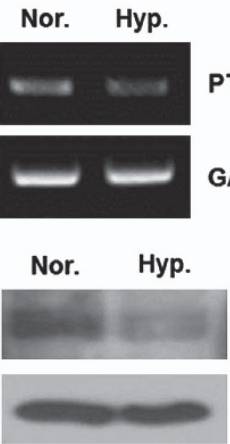

PTPN2

$\beta$-actin

\section{PTPN2}

GAPDH

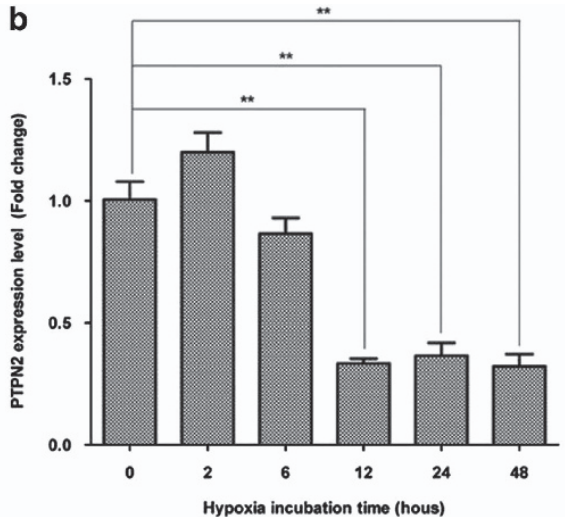

c

Hypoxia incubation time (hous)

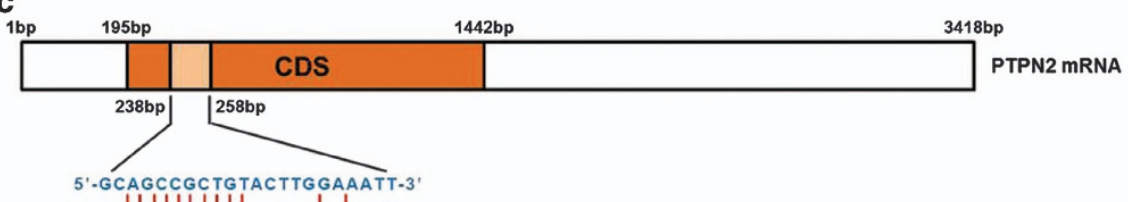

e NC mimic
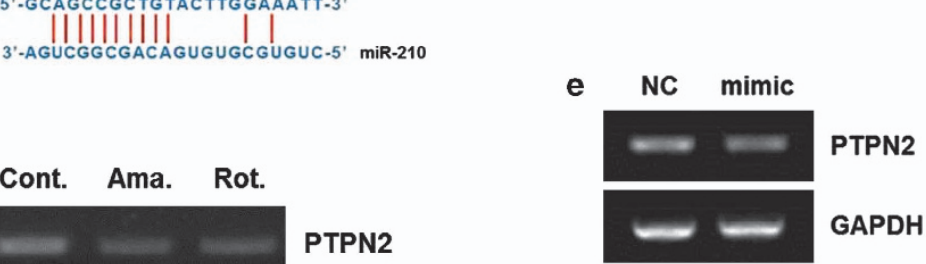

d Cont. Ama. Rot.
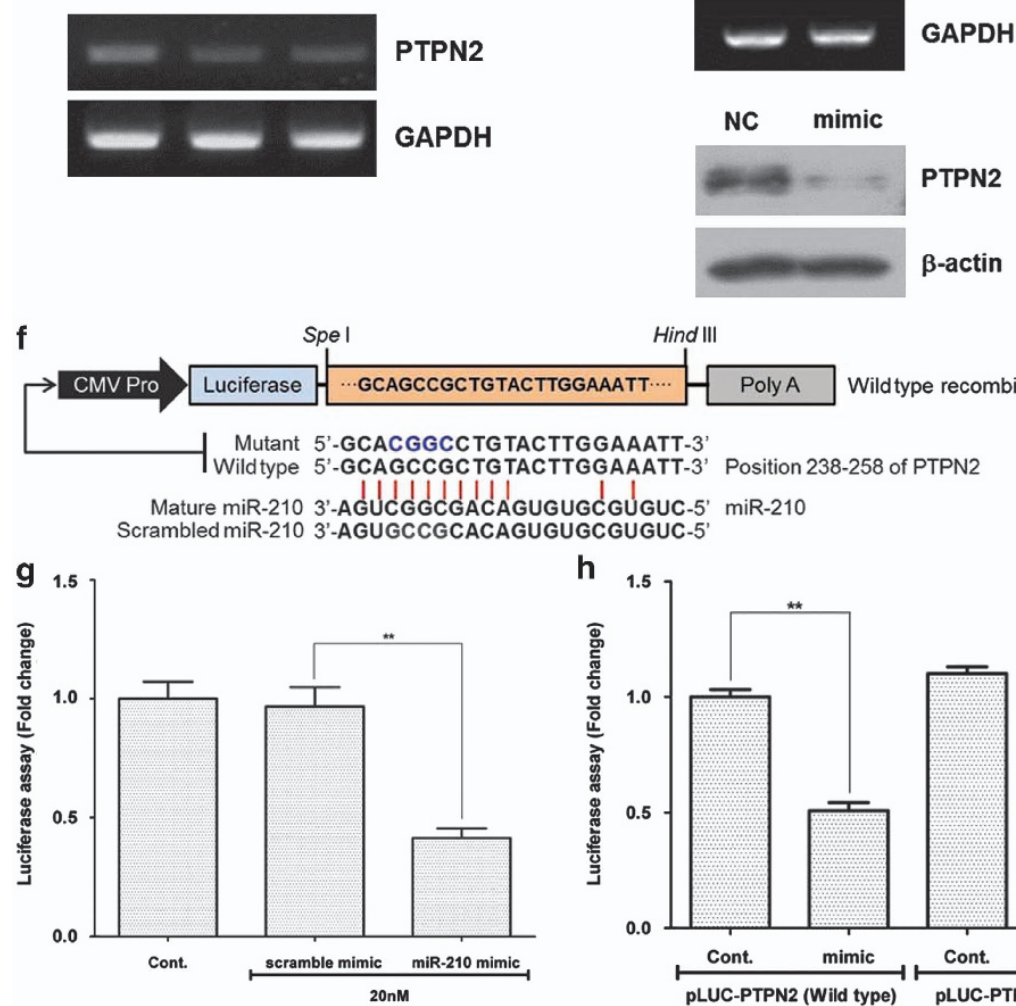

Figure 7 PTPN2 downregulation by miR-210. mRNA expression of PTPN2 was downregulated by ROS generation and miR-210 mimic treatment in ASCs. PTPN2 was found to be a direct target of miR-210 in luciferase activity assay, and it regulates the proliferation/migration of ASCs. (a) PTPN2 mRNA and protein levels were downregulated at $24 \mathrm{~h}$ after hypoxia (Hyp.). (b) Temporal profile of PTPN2 was measured by Q-PCR, and it decreased during hypoxia. (c) Complementary nucleotide sequences between PTPN2 and miR-210. (d) Antimycin (Ama.) (10 nM) and rotenone (Rot.) (10 pM) also downregulated PTPN2 mRNA. (e) Transfection of miR-210 mimic (20 nM) downregulated PTPN2 mRNA and protein levels. (f-h) Using luciferase activity assay in HEK293 cells, we investigated whether or not PTPN2 is a direct target of miR-210. Scheme of luciferase activity assay (f). miR-210 mimic significantly reduced the PTPN2 luciferase activity in HEK293 cells (g). Although miR-210 reduced the luciferase activity of wildtype PTPN2, it did not reduce the mutant PTPN2 in HEK293 cells (h). (i, j) Ethyl-3,4-dephosphostatin, a PTPN2 inhibitor, increased the proliferation (i) and migration (j) of ASC. (k, I) However, transfection of PTPN2 cDNA significantly reduced the hypoxia-induced proliferation (k) and migration (I) of ASCs ${ }^{*} P<0.01$. Cont, control; CMV, cytomegalovirus; GAPDH, glyceraldehyde 3-phosphate dehydrogenase; NC, negative control; Nor., normaxia; Hyp., hypoxia 

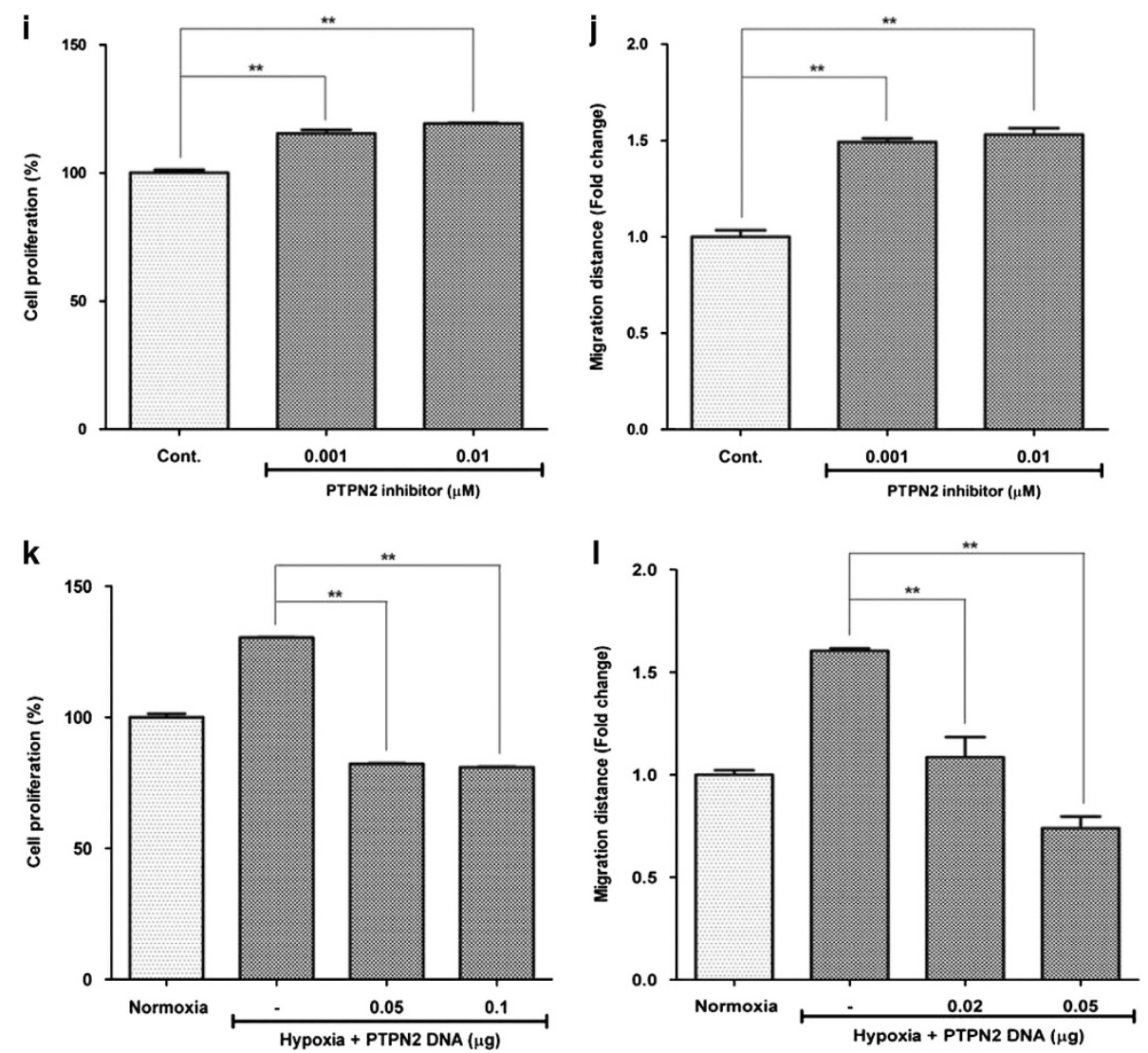

Figure 7 (Continued)

but not PDGFR- $\alpha .^{28}$ Furthermore, we first found in this study that there is a positive feed-forward loop between PDGFR- $\beta$ activation and PTPN2 downregulation, and it is mediated by Akt or ERK pathway, and miR-210 upregulation (Supplementary Scheme 1).

Growth factors are added to the culture medium to maintain the self-renewal capability and to increase the proliferation of stem cells. ${ }^{42-45}$ In a previous study, we tested and compared the proliferating effects of six growth factors (i.e. PDGF-AA, PDGF-BB, VEGF, insulin-like growth factor, basic fibroblast growth factor and epidermal growth factor) in ASCs. ${ }^{46}$ Among them, PDGF-BB showed the best stimulatory effect on ASC proliferation at a physiologically relevant level (at $10 \mathrm{ng} / \mathrm{ml}$ ). Compared with PDGF-AA and other growth factors, PDGF-BB treatment highly induces ROS generation and miR-210 level, and it might be responsible for the highest proliferative effect of PDGF-BB in ASCs.

In addition to hypoxia, ROS generation from diverse sources (mitochondrial ROS donors and PDGF-BB) induces miR-210 expression; therefore, it can be regarded as ROSresponsive microRNA. PDGFR- $\beta$, Akt and ERK1/2 molecules are involved in ROS-induced signaling cascades, and NF- $k \mathrm{~b}$ and Elk1 induce the transcription of miR-210. PTPN2 and ISCU2 are found to be a direct target of miR-210, which collectively mediates miR-210-induced ROS generation and proliferation/migration of ASCs.
Materials and Methods

Cell culture and inhibition study. ASCs were isolated from lipoaspiration of subcutaneous adipose tissue. Characterization of ASCs was performed by trans-differentiation and analysis of cell surface markers using flow cytometry. ${ }^{47,48}$ ASCs were cultured in $\alpha$-minimum essential medium (Gibco, Invitrogen, Carlsbad, CA, USA) with $10 \%$ fetal bovine serum (Gibco), $1 \%$ penicillin and streptomycin (Gibco) at $37^{\circ} \mathrm{C}$ in a humidified $5 \% \mathrm{CO}_{2}$ (i.e. normoxia), or $5 \% \mathrm{CO}_{2}, 2 \% \mathrm{O}_{2}$ and balanced $\mathrm{N}_{2}$ (i.e. hypoxia).

For the inhibition study, 0.1 mM NAC (ROS scavenger; Sigma-Aldrich, St. Louis, MO, USA), 50 and $100 \mu \mathrm{M}$ YC-1 (an HIF-1 $\alpha$ inhibitor; Sigma), $5 \mu \mathrm{M}$ LY294002 (PI3K/Akt inhibitor; Calbiochem, San Diego, CA, USA), $5 \mu \mathrm{M}$ U0126 (MAPK/ERK inhibitor; Calbiochem), $10 \mu \mathrm{M}$ AG1296 (PDGFR inhibitor; Calbiochem) and 0.001-1 $\mu \mathrm{M}$ ethyl-3,4-dephostatin (PTPN2 inhibitor; Santa Cruz Biotechnology, Santa Cruz, CA, USA) were used.

Measurement of miR-210 expression level. Total cellular RNA was extracted with TRIzol reagent (Invitrogen), followed by a reverse transcription using miRNA First-Strand Synthesis Kit (Clonetech, Mountain View, CA, USA). cDNA was synthesized from $500 \mathrm{ng}$ of total RNA using mRQ enzyme. The miR-210 expression level was measured by Q-PCRs, using $10 \mu \mathrm{M}$ of the miR-210 primer (Genolution, Seoul, Korea) and quantitect SYBR green (Qiagen, Hilden, Germany). The Q-PCR was performed using StepOne real-time PCR system (Applied Biosystems, Carlsbad, CA, USA) under the following steps: initial denaturation step at $94^{\circ} \mathrm{C}$ for $5 \mathrm{~min}, 40$ thermal cycling step consisted of $30 \mathrm{~s}$ at $94^{\circ} \mathrm{C}, 30 \mathrm{~s}$ at $56^{\circ} \mathrm{C}$ and $30 \mathrm{~s}$ at $72{ }^{\circ} \mathrm{C}$, and a final extension step at $72{ }^{\circ} \mathrm{C}$ for 5 min for termination. For miR-210 quantification, analysis of fold change was calculated by using $\Delta \mathrm{Ct}$ value, relative to the level of U6 snRNA.

miR-210 mimic or inhibitor transfection. ASCs were seeded with complete medium without antibiotics. On the following day, confluent ASCs were 
kept in serum-free medium without antibiotics for $2 \mathrm{~h}$. Then, miR-210 mimic or inhibitor $(10,20$ or $50 \mathrm{nM}$; Genolution) was transfected to ASC using Lipofectamine 2000 (Invitrogen).

siRNA or PTPN2 transfection. ASCs were seeded with complete medium without antibiotics. On the following day, confluent ASCs were kept in serum-free medium without antibiotics for $2 \mathrm{~h}$. Then, siRNA for PDGFR- $\beta$, Akt, ERK and ISCU1/2 (20 nM; Santa Cruz Biotechnology), or PTPN2 cDNA clone $(0.02,0.05$ and $0.1 \mu \mathrm{g}$; Origene, Rockville, MD, USA) were transfected to ASCs using Lipofectamine 2000 (Invitrogen). Cells were incubated for 24 or $48 \mathrm{~h}$ after siRNA or cDNA transfection.

ROS generation assay. Intracellular ROS production was measured using DCF-DA (Molecular Probes, Eugene, OR, USA). ASCs were seeded in 60-mm culture dish. Cells were transfected with miR-210 mimic, inhibitor or siRNA for $24 \mathrm{~h}$ and were incubated with DCF-DA $(20 \mu \mathrm{M})$ for $20 \mathrm{~min}$ at $37^{\circ} \mathrm{C}$ in the dark place. After incubation, cells were harvested by trypsin-EDTA solution. Then, cell suspensions were collected in a centrifuge and the supernatant was removed. Fluorescence images were taken after DCF-DF staining by fluorescence microscopy (ECLIPSE E600; Nikon, Tokyo, Japan). Otherwise, fluorescence intensity of DCF-DA was measured and calculated using flow cytometry (Becon Dickinson, Franklin Lakes, NJ, USA)

Proliferation assay. ASCs were seeded in 24-well plates and transfected with miR-210 mimic, inhibitor or siRNA. After $48 \mathrm{~h}$ incubation, the medium was removed and cell number was measured using CCK-8 assay kit (Dojindo, Gaithersburg, MD, USA). CCK-8 solution $(150 \mu \mathrm{l})$ was added to each well and incubated for $2 \mathrm{~h}$. After the incubation, the absorbance was measured at $450 \mathrm{~nm}$ using a microplate reader (Tecan, Grodig, Austria).

Migration assay. To determine the migration rate of ASCs, ASCs were seeded in six-well plates with complete medium. On the following day, confluent ASCs were kept in serum-free medium for 12 or $24 \mathrm{~h}$. Serum-free/starved ASCs were wounded using migration micropipette tip, and were transfected with miR-210 mimic, inhibitor or siRNA. At $24 \mathrm{~h}$ after the wounding, cell migration was determined by bright-field microscopic examination. For the evaluation of ASC migration, five randomly selected points along each wound were marked, and the horizontal distance of migrating cells from the initial wound was measured.

Reverse transcription-polymerase chain reaction. Total cellular RNA was extracted with TRIzol reagent (Invitrogen), followed by a reverse transcription with CDNA synthesis kit (Promega, Madison, WI, USA). cDNA was synthesized from $500 \mathrm{ng}$ of total RNA using $200 \mathrm{U}$ of reverse transcriptase (M-MLV RT) and $50 \mathrm{ng} / \mu \mathrm{l}$ oligo(dT). PCRs were performed in a final volume of $30 \mu \mathrm{l}$ reaction mixture that contained $\mathrm{RT}$ reaction mixture, DTT, $1.25 \mathrm{mM} \mathrm{dNTP}, 10 \mathrm{pM}$ of each primer and $0.5 \mathrm{U}$ of polymerase (Promega). The RT-PCR was performed under the following steps: initial denaturing step at $94^{\circ} \mathrm{C}$ for $5 \mathrm{~min}, 35$ thermal cycling step consisted of $30 \mathrm{~s}$ at $94^{\circ} \mathrm{C}, 30 \mathrm{~s}$ at $56^{\circ} \mathrm{C}$ and $30 \mathrm{~s}$ at $72{ }^{\circ} \mathrm{C}$, and then final extension step at $72^{\circ} \mathrm{C}$ for $5 \mathrm{~min}$ for termination. GADPH mRNA level was used for sample standardization. After running with $1.5 \%$ agarose-gel electrophoresis, each band was quantified by the densitometer (Bio-Rad Laboratories, Hercules, CA, USA). Primers used in this study were as follows: Oct4 - forward, $5^{\prime}$-ACCTTCCAATGTGGAGCATC- $3^{\prime}$ and reverse, $5^{\prime}$-GAATTTGGCTGGAAC TGCA-3'; Rex1 - forward, 5'-GCTTCTTCCGGGCCATTGACTG-3' and reverse, $5^{\prime}$-TTGTAGGGGTCGTAACCCAGCC-3'; and PTPN2 - forward, $5^{\prime}$-TTCCTCTGA ACCCCAAACTG-3' and reverse, $5^{\prime}$-GCCTCCAAAAACAAATCCTG- $3^{\prime}$; and GAPDH - forward, 5'-CGAGATCCCTCCAAAATCAA-3' and reverse, $5^{\prime}$-TGTGGTCATGAGTCCTTCCA-3'.

Antibodies. Antibodies recognizing PDGFR- $\beta(1: 2000)$, phospho-PDGFR- $\beta$ (1:1000), AKT $(1: 3000)$, phospho-AKT $(1: 2000)$, ERK $(1: 3000)$ and phosphoERK $(1: 3000)$ were purchased from Cell Signaling Technology (Denvers, MA USA). HIF- $1 \alpha(1: 1000)$ was purchased from BD Bioscience (San Jose, CA, USA). ISCU1/2 (1:1000), horseradish-peroxidase (HRP)-conjugated secondary mouse antibody $(1: 10000)$ and HRP-conjugated secondary rabbit antibody $(1: 10000)$ were purchased from Santa Cruz Biotechnology.

Western blotting. Total proteins of ASCs were isolated using SDS sample buffer. Lysates were loaded by 10 or $8 \%$ SDS-PAGE and transferred to a PVDF membrane (Millipore, Bedford, MA, USA). The membrane was blocked with $5 \%$ skim milk for $1 \mathrm{~h}$ at room temperature and then incubated with primary antibody at $4{ }^{\circ} \mathrm{C}$ for $24 \mathrm{~h}$. On the following day, the membrane was washed with TBS-T $(0.1 \%$ Tween-20 in Tris-buffered saline) and then incubated with HRP-conjugated secondary antibody for $1 \mathrm{~h}$. The membrane was also reacted with the ECL solution (Millipore) and developed in an X-ray film.

ChIP assay. ASCs (passase $5,2 \times 10^{6}$ cells) were treated with antimycin $(10 \mathrm{nM})$ or rotenone $(10 \mathrm{pM})$ for $24 \mathrm{~h}$ and fixed with $1 \%$ formaldehyde for $10 \mathrm{~min}$ at room temperature. Glycine $(0.125 \mathrm{M})$ was added to quench the crosslink. Cells were sonicated on ice to obtain homnogeneous DNA between 200 and $1000 \mathrm{bp}$. Immuprecipitation was performed with mock IgG, anti-pElk antibody and anti-p-NF $\kappa B$ p50 antibody in the presence of protein A/G agarose mixture. The protein-DNA complex was washed, eluted and heated at $65^{\circ} \mathrm{C}$ with proteinase $\mathrm{K}$ to remove proteins. DNA was purified with the Labopass Clean-up Kit (COSMO Genetech, Seoul, Korea), and used for PCR (detection for Elk binding region: forward, 5'-ACGCGGGTGCGGGGCACGGAGGC-3'; reverse, 5'-CGGATGGTACGGCCCGA GGTGG-3'; detection for NF- $\kappa$ B p50 binding region: forward, $5^{\prime}$-GGGCCGGG GGGCGAGAGGGTGCCA-3'; reverse, 5' ${ }^{\prime}$-TCCCCTCCAACTTGGGCGTCCGAG-3').

Luciferase activity assay. For luciferase activity assay, wild-type and mutant oligomers covering 238-258 bp of PTPN2 (NM_002828.3) were synthesized from Bioneer (Seoul, Korea), and cloned into Spel/Hindll of pLUC3UTR vector (Signosis, Sunnyvale, CA, USA). HEK293 cells $\left(5 \times 10^{5}\right)$ were seeded into 12-well plates and transfected with luciferase reporter vectors containing $238-258 \mathrm{bp}$ regions of PTPN2 $(0.3 \mu \mathrm{g})$, and Renilla vector $(0.1 \mu \mathrm{g})$, in the presence of human miR-210 or scrambled human miR-210 $(20 \mathrm{nM})$ as indicated (Figure 7f), and then cultured for $24 \mathrm{~h}$. Thereafter, the cells were harvested using reporter lysis buffer and luciferase activity was determined by Dual-Luciferase Assay System Kit (Promega, Fitchburg, WI, USA) and quantified using GLOMAX (Promega) according to the manufacturer's instructions. Luciferase activity was normalized by Renilla luciferase activity.

Statistical analysis. All data were representative of triplicate independent experiments. The statistical significance of the differences among groups was tested using the ANOVA or Student's t-test. $P<0.01$ is considered to be significant.

\section{Conflict of Interest}

The authors declare no conflict of interest.

Acknowledgements. This study was supported by grants from basic science research program through the National Research Foundation of Korea funded by the Ministry of Education, Science and Technology (2011-0019636 and 2012-003803).

1. Lee EY, Xia Y, Kim WS, Kim MH, Kim TH, Kim KJ et al. Hypoxia-enhanced wound-healing function of adipose-derived stem cells: increase in stem cell proliferation and up-regulation of VEGF and bFGF. Wound Repair Regen 2009; 17: 540-547.

2. Song SY, Chung HM, Sung JH. The pivotal role of VEGF in adipose-derived-stem-cellmediated regeneration. Expert Opin Biol Ther 2010; 10: 1529-1537.

3. Wei X, Du Z, Zhao L, Feng D, Wei G, He Y et al. IFATS collection: the conditioned media of adipose stromal cells protect against hypoxia-ischemia-induced brain damage in neonatal rats. Stem Cells 2009; 27: 478-488.

4. Eto $\mathrm{H}$, Suga $\mathrm{H}$, Inoue K, Aoi $\mathrm{N}$, Kato $\mathrm{H}$, Araki J et al. Adipose injury-associated factors mitigate hypoxia in ischemic tissues through activation of adipose-derived stem/progenitor/ stromal cells and induction of angiogenesis. Am J Pathol 2011; 178: 2322-2332.

5. Gao W, Qiao X, Ma S, Cui L. Adipose-derived stem cells accelerate neovascularization in ischaemic diabetic skin flap via expression of hypoxia-inducible factor-1alpha. J Cell $\mathrm{Mol}$ Med 2011; 15: 2575-2585.

6. Rehman J, Traktuev D, Li J, Merfeld-Clauss S, Temm-Grove CJ, Bovenkerk JE et al. Secretion of angiogenic and antiapoptotic factors by human adipose stromal cells. Circulation 2004; 109: 1292-1298.

7. Park SG, Kim JH, Xia Y, Sung JH. Generation of reactive oxygen species in adiposederived stem cells: friend or foe? Expert Opin Ther Targets 2011; 15: 1297-1306.

8. Kim JH, Park SH, Park SG, Choi JS, Xia Y, Sung JH. The pivotal role of reactive oxygen species generation in the hypoxia-induced stimulation of adipose-derived stem cells. Stem Cells Dev 2011; 20: 1753-1761.

9. Semenza GL. HIF-1 and mechanisms of hypoxia sensing. Curr Opin Cell Biol 2001; 13: 167-171.

10. Semenza GL. HIF-1: mediator of physiological and pathophysiological responses to hypoxia. J Appl Physiol 2000; 88: 1474-1480. 
11. Wang H, Bian S, Yang CS. Green tea polyphenol EGCG suppresses lung cancer cell growth through upregulating miR-210 expression caused by stabilizing HIF-1alpha. Carcinogenesis 2011; 32: 1881-1889.

12. Corn PG. Hypoxic regulation of miR-210: shrinking targets expand HIF-1's influence. Cancer Biol Ther 2008; 7: 265-267.

13. Nakada C, Tsukamoto Y, Matsuura K, Nguyen TL, Hijiya N, Uchida T et al. Overexpression of miR-210, a downstream target of HIF1alpha, causes centrosome amplification in renal carcinoma cells. J Pathol 2011; 224: 280-288.

14. Ivan M, Harris AL, Martelli F, Kulshreshtha R. Hypoxia response and microRNAs: no longer two separate worlds. J Cell Mol Med 2008; 12: 1426-1431.

15. Fasanaro P, Greco S, Lorenzi M, Pescatori M, Brioschi M, Kulshreshtha R et al. An integrated approach for experimental target identification of hypoxia-induced miR-210. J Biol Chem 2009; 284: 35134-35143.

16. Hu S, Huang M, Li Z, Jia F, Ghosh Z, Lijkwan MA et al. MicroRNA-210 as a novel therapy for treatment of ischemic heart disease. Circulation 2010; 122(Suppl II): S124-S131.

17. Chan SY, Zhang YY, Hemann C, Mahoney CE, Zweier JL, Loscalzo J. MicroRNA-210 controls mitochondrial metabolism during hypoxia by repressing the iron-sulfur cluster assembly proteins ISCU1/2. Cell Metab 2009; 10: 273-284.

18. Zhang Z, Sun H, Dai H, Walsh RM, Imakura M, Schelter J et al. MicroRNA miR-210 modulates cellular response to hypoxia through the MYC antagonist MNT. Cell Cycle 2009; 8: $2756-2768$.

19. Zhang $Y$, Fei M, Xue G, Zhou Q, Jia Y, Li L et al. Elevated levels of hypoxia-inducible microRNA-210 in pre-eclampsia: new insights into molecular mechanisms for the disease. $J$ Cell Mol Med 2012; 16: 249-259.

20. Xiong L, Wang F, Huang X, Liu ZH, Zhao T, Wu LY et al. DNA demethylation regulates the expression of miR-210 in neural progenitor cells subjected to hypoxia. FEBS J 2012; 279: 4318-4326.

21. Chen Z, Li Y, Zhang H, Huang P, Luthra R. Hypoxia-regulated microRNA-210 modulates mitochondrial function and decreases ISCU and COX10 expression. Oncogene 2010; 29: 4362-4368.

22. Favaro E, Ramachandran A, McCormick R, Gee H, Blancher C, Crosby M et al. MicroRNA210 regulates mitochondrial free radical response to hypoxia and Krebs cycle in cancer cells by targeting iron sulfur cluster protein ISCU. PLOS One 2010; 5: e10345.

23. Kim JH, Jee MK, Lee SY, Han TH, Kim BS, Kang KS et al. Regulation of adipose tissue stromal cells behaviors by endogenic Oct4 expression control. PLoS One 2009; 4: e7166.

24. Bhandari DR, Seo KW, Roh KH, Jung JW, Kang SK, Kang KS. REX-1 expression and p38 MAPK activation status can determine proliferation/differentiation fates in human mesenchymal stem cells. PLoS One 2010; 5: e10493.

25. Neal CS, Michael MZ, Rawlings LH, Van der Hoek MB, Gleadle JM. The VHL-dependent regulation of microRNAs in renal cancer. BMC Med 2010; 8: 64.

26. Baek SJ, Kang SK, Ra JC. In vitro migration capacity of human adipose tissue-derived mesenchymal stem cells reflects their expression of receptors for chemokines and growth factors. Exp Mol Med 2011; 43: 596-603.

27. Persson C, Savenhed C, Bourdeau A, Tremblay ML, Markova B, Bohmer FD et al. Siteselective regulation of platelet-derived growth factor beta receptor tyrosine phosphorylation by T-cell protein tyrosine phosphatase. Mol Cell Biol 2004; 24: 2190-2201.

28. Karlsson S, Kowanetz K, Sandin A, Persson C, Ostman A, Heldin CH et al. Loss of T-cell protein tyrosine phosphatase induces recycling of the platelet-derived growth factor (PDGF) beta-receptor but not the PDGF alpha-receptor. Mol Biol Cell 2006; 17: 4846-4855.

29. Bartel DP. MicroRNAs: genomics, biogenesis, mechanism, and function. Cell 2004; 116 : 281-297.

30. Rana TM. Illuminating the silence: understanding the structure and function of small RNAs. Nat Rev Mol Cell Biol 2007; 8: 23-36.

31. Chan SY, Loscalzo J. MicroRNA-210: a unique and pleiotropic hypoxamir. Cell Cycle 2010; 9: $1072-1083$
32. Higuchi M, Dusting G, Peshavariya H, Jiang F, Hsiao ST, Chan E et al. Differentiation of human adipose-derived stem cells into fat involves reactive oxygen species and forkhead box 01 mediated upregulation of antioxidant enzymes. Stem Cells Dev 22: 878-888 2012.

33. Tormos KV, Anso E, Hamanaka RB, Eisenbart J, Joseph J, Kalyanaraman B et al. Mitochondrial complex III ROS regulate adipocyte differentiation. Cell Metab 2011; 14: 537-544.

34. Schroder K, Wandzioch K, Helmcke I, Brandes RP. Nox4 acts as a switch between differentiation and proliferation in preadipocytes. Arterioscler Thromb Vasc Biol 2009; 29: 239-245.

35. Qin L, Chen $Y$, Niu Y, Chen W, Wang $Q$, Xiao $S$ et al. A deep investigation into the adipogenesis mechanism: profile of microRNAs regulating adipogenesis by modulating the canonical Wnt/beta-catenin signaling pathway. BMC Genom 2010; 11: 320.

36. Li Y, Mouche S, Sajic T, Veyrat-Durebex C, Supale R, Pierroz D et al. Deficiency in the NADPH oxidase 4 predisposes towards diet-induced obesity. Int J Obes (Lond) 2012; 36: 1503-1513.

37. Kelly TJ, Souza AL, Clish CB, Puigserver P. A hypoxia-induced positive feedback loop promotes hypoxia-inducible factor 1alpha stability through miR-210 suppression of glycerol-3-phosphate dehydrogenase 1-like. Mol Cell Biol 2011; 31: 2696-2706.

38. Kulshreshtha R, Ferracin M, Wojcik SE, Garzon R, Alder H, Agosto-Perez FJ et al. A microRNA signature of hypoxia. Mol Cell Biol 2007; 27: 1859-1867.

39. Mutharasan RK, Nagpal V, Ichikawa Y, Ardehali H. MicroRNA-210 is upregulated in hypoxic cardiomyocytes through Akt- and p53-dependent pathways and exerts cytoprotective effects. Am J Physiol Heart Circ Physiol 2011; 301: H1519-H1530.

40. Neel BG, Tonks NK. Protein tyrosine phosphatases in signal transduction. Curr Opin Cell Biol 1997; 9: 193-204.

41. Ostman A, Bohmer FD. Regulation of receptor tyrosine kinase signaling by protein tyrosine phosphatases. Trends Cell Biol 2001; 11: 258-266.

42. Kang YJ, Jeon ES, Song HY, Woo JS, Jung JS, Kim YK et al. Role of c-Jun N-terminal kinase in the PDGF-induced proliferation and migration of human adipose tissue-derived mesenchymal stem cells. J Cell Biochem 2005; 95: 1135-1145.

43. Willerth SM, Rader A, Sakiyama-Elbert SE. The effect of controlled growth factor delivery on embryonic stem cell differentiation inside fibrin scaffolds. Stem Cell Res 2008; 1: 205-218.

44. Levenstein ME, Ludwig TE, Xu RH, Llanas RA, VanDenHeuvel-Kramer K, Manning D et al. Basic fibroblast growth factor support of human embryonic stem cell self-renewal. Stem Cells 2006; 24: 568-574.

45. Ball SG, Shuttleworth A, Kielty CM. Inhibition of platelet-derived growth factor receptor signaling regulates Oct4 and Nanog expression, cell shape, and mesenchymal stem cell potency. Stem Cells 2012; 30: 548-560.

46. Kaewsuwan S, Song SY, Kim JH, Sung JH. Mimicking the functional niche of adiposederived stem cells for regenerative medicine. Expert Opin Biol Ther 2012; 12: 1575-1588.

47. Kim WS, Park BS, Kim HK, Park JS, Kim KJ, Choi JS et al. Evidence supporting antioxidan action of adipose-derived stem cells: protection of human dermal fibroblasts from oxidative stress. J Dermatol Sci 2008; 49: 133-142.

48. Kim WS, Park BS, Sung JH, Yang JM, Park SB, Kwak SJ et al. Wound healing effect of adipose-derived stem cells: a critical role of secretory factors on human dermal fibroblasts. J Dermatol Sci 2007; 48: 15-24

(i) ()) $€$ Cell Death and Disease is an open-access journal published by Nature Publishing Group. This work is licensed under a Creative Commons Attribution-NonCommercialNoDerivs 3.0 Unported License. To view a copy of this license, visit http://creativecommons.org/licenses/by-nc-nd/3.0/

Supplementary Information accompanies this paper on Cell Death and Disease website (http://www.nature.com/cddis) 